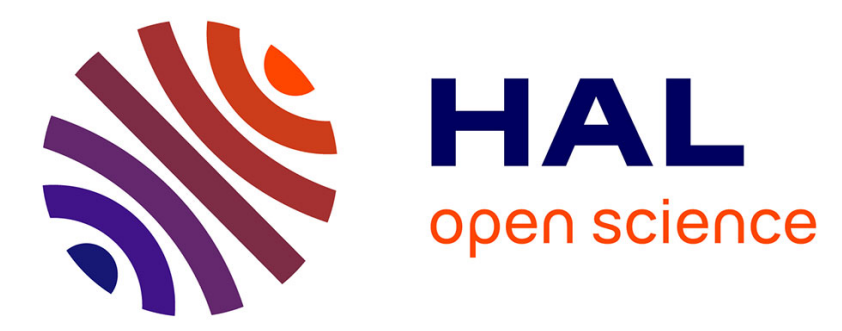

\title{
A Cellular Potts energy-based approach to analyse the influence of the surface topography on single cell motility
}

Thomas Thenard, Anita Catapano, Michel Mesnard, Rachele Allena

\section{To cite this version:}

Thomas Thenard, Anita Catapano, Michel Mesnard, Rachele Allena. A Cellular Potts energy-based approach to analyse the influence of the surface topography on single cell motility. Journal of Theoretical Biology, 2021, 509, pp.1-19. 10.1016/j.jtbi.2020.110487 . hal-03156699

\section{HAL Id: hal-03156699 \\ https://hal.science/hal-03156699}

Submitted on 2 Mar 2021

HAL is a multi-disciplinary open access archive for the deposit and dissemination of scientific research documents, whether they are published or not. The documents may come from teaching and research institutions in France or abroad, or from public or private research centers.
L'archive ouverte pluridisciplinaire HAL, est destinée au dépôt et à la diffusion de documents scientifiques de niveau recherche, publiés ou non, émanant des établissements d'enseignement et de recherche français ou étrangers, des laboratoires publics ou privés. 


\title{
A Cellular Potts energy-based approach to analyse the influence of the surface topography on single cell motility
}

\author{
Thomas Thenard ${ }^{\mathrm{a}, \mathrm{b}, *}$, Anita Catapano $^{\mathrm{b}}$, Michel Mesnard ${ }^{\mathrm{c}}$, Rachele Allena ${ }^{\mathrm{a}}$ \\ ${ }^{a}$ Arts et Metiers Institute of Technology, Université Paris 13, Sorbonne Paris Cité, IBHGC, HESAM Université, F-75013 Paris, France \\ b Bordeaux INP, Université de Bordeaux, Arts et Métiers Institute of Technology, CNRS, INRA, HESAM Université, I2M UMR 5295, F-33405 Talence, France \\ ' Arts et Métiers Institute of Technology, Université de Bordeaux, CNRS, INRA, Bordeaux INP, HESAM Université, I2M UMR 5295, F-33405 Talence, France
}

Keywords:

Cell migration

Cellular Potts model

Surface roughness

Contact surface

\begin{abstract}
A B S T R A C T
The surface shape is an important aspect to take into account to ensure the success of an implant. At the cellular scale level, the cell behaviour, especially its migration, is affected by the specificities of the surface of the substrate, such as the stiffness of the surface and its roughness topography. The latter has been shown to have a great impact on various cell mechanisms, such as the cell adhesion, migration, or proliferation. In fact, the mere presence of micro roughness leads to an improvement of those mechanisms, with a better integration of the implants. However, the phenomena behind those improvements are still not clear.

In this paper, we propose a three-dimensional (3D) model of a single cell migration using a Cellular Potts (CP) model to study the influence of the surface topography on cell motility. To do so, various configurations were tested, such as: (i) a substrate with a random roughness, (ii) a substrate with a rectangular groove pattern (parallel and perpendicular to the direction of motion), (ii) a substrate with a sinusoidal groove pattern. To evaluate the influence of the surface topography on cell motility, for each configuration, the cell speed and shape as well as the contact surface between the cell and the substrate have been quantified.

Our numerical results demonstrate that, in agreement with the experimental observations of the literature, the substrate topography has an influence on the cell efficiency (i.e. cell speed), orientation and shape. Besides, we also show that the increase of the contact surface alone in presence of roughness is not enough to explain the improvement of cell migration on the various rough surfaces. Finally, we highlight the importance of the roughness dimension on cell motility. This could be a critical aspect to consider for further analyses and applications, such as surface treatments for medical applications.
\end{abstract}

\section{Introduction}

Implant placement have skyrocketed in the world for a few decades (for instance, $>450,000$ dental implants that are being placed every year in the US (Gaviria et al., 2014). The proper functioning of each implant is given by a good integration in the patient body as well as a good stability. This stability is firstly set by a primary connexion to anchor the implant to the bone, and secondly, by a secondary connexion with the creation of new bone tissues around the implant. The latter connexion is then defined as the osseointegration (Albrektsson et al., 1978) and a good comprehension of this process assures the implantation success. The osseointegration depends on various parameters, such as the properties of the

\footnotetext{
* Corresponding author.

E-mail address: thomas.thenard@ensam.eu (T. Thenard).
}

implant (mechanical, topological...), the condition of the bone in the implantation site, or the chirurgical technique. Among those factors, surface conditions have a significant impact on the osseointegration. Indeed, it plays a role in the bone response on the surface of the implant during the initial phase of bone remodelling, by improving or inhibiting it. Thus, a good osteointegration requires a control of the surface conditions.

The literature proposes a significant number of studies that described the influence of the surface conditions on bone remodelling. The work of Albrektsson et al. (1981) showed that the presence of micro roughness (i.e. geometry defects at the microscale) led to a speeding of the healing time, compared to a smooth surface. The study of Liddell et al. (2017) pointed out an improved clamping of the bone to the implant on surfaces with nano and micro roughness. Besides, Wennerberg et al. (2009) went further by showing that a moderate roughness, between 1 and $2 \mu \mathrm{m}$, gave 
an enhanced bone response. However, this influence is not limited to the bone tissue only; it also affects the bone cell behavior itself. Indeed, the surface characteristics of the implant play an important role in the promotion or inhibition of the cell adhesion, motility, and shape, which are essential for an efficient early osseointegration. Huang et al. (2004) registered an increase in cell adhesion with an increasing roughness on ground titanium, highlighting the role played by the roughness in cell-substrate interaction. The same observation was made in for other cellular mechanisms such as the cell migration and proliferation (Anselme et al., 2000, 2014; Andrukhov, 2016; Wu et al., 2015). Other studies displayed the effects of the surface rigidity on the self-organization of the cell (Lo et al., 2000; Chang et al., 2017; Discher et al., 2005; Raab et al., 2012). Surface topography also significantly affects the cell response. Many studies showed that roughness with a periodic topography (groove, porosity...) affected both the cell adhesion and motility, by affecting the spreading, the polarization, and the focal adhesion (FA) formation (Novaes et al., 2010; Lamers, 2010; Kaiser et al., 2006).

Such results confirm that cell sense and respond to the surface topography by modifying their morphology and behaviour (i.e. shape and speed), but the reasons behind such a process are still unknown. On the one hand, one can assume that the increase of the roughness (i.e. the increase of the substrate area) may improve the cell contact surface with the substrate (Gallant et al., 2005), making it easier for the cell to move on the surface. On the other hand, the cell may be more likely to migrate thanks to a local increase of the adhesion strength with the substrate due to the roughness (Ponsonnet, et al., 2003). Additionally, the orientation of the surface shape, compared to the direction of motion of the cell, has also to be taken into account. Evaluating the influence of all these parameters with a full control of the environment can be too costly and, in some cases, some parameters can be interdependent. Thus, the numerical models could help and be an alternative approach.

Some numerical studies analysed the cell behaviour on fibronectin pattern. Kim et al. (2013) proposed a three dimensional (3D) integrative cell migration model incorporating FA, cytoskeleton, and nucleus remodelling, in order to study cell spreading and migration on various patterns. Their results showed that cell migration and spreading depend on fibronectin concentration, as well as higher stress concentration of the membrane on sharp surface. Similarly, Albert et al. (2014) did the same analysis, but using a two dimensional (2D) Cellular Potts (CP) model a lattice-based stochastic method employing energy minimization (Graner et al., 1992; Swat et al., 2012). They were able to obtain similar results to Kim et al with a reduced computation time. The model of Scianna et al. (2013), based on a CP approach, analysed the influence of the extra cellular matrix (ECM) orientation and it showed that the cell adapts its shape to the ECM orientation. Knowing that ECM orientation is guided by the surface orientation, the geometrical influence of the roughness can be assumed. If we focus at a subcellular scale, Chong et al. (2016) and Decuzzi et al. (2010) proposed each a model of the contact adhesion between the cell membrane and the surface topography using an analytical approach. The results pointed out an increase or decrease of the contact adhesion depending on the topography of the surface. All these numerical and analytical studies are very interesting and provide consistent results with respect to the existing experimental data. Nonetheless, none of them considered the underneath roughness and its effects on the cell motility.

Here, we present a 3D CP model to simulate the migration of a single cell on surfaces with different topographical properties. To our knowledge, this is the first time the CP method is employed to study the impact of surface roughness on cell motility. Our main objective is to quantitively analyse the influence of the topography parameters on the cell motility in terms of cell speed, shape and contact surface. In the next section (Section 2), we will define the main equations of the model and various surface topologies, such as: (i) a random rough surface, (ii) surfaces with a rectangular groove pattern with variable width and depth, and (iii) surfaces with a sinusoidal groove pattern with variable wavelength and amplitude. These surfaces are tested in Section 3 and we analyse both the cell shape and the cell speed in order to assess the influence of the surface topography on the overall cell behaviour. Then, such results will be discussed and compared to specific experimental data taken from the literature to qualitatively validate the numerical approach.

\section{Materials and methods}

\subsection{CP model}

In the present work, we employ a CP model, a grid-based and energetic stochastic approach, developed by Graner et al. (1992). A 3D regular lattice $\Omega \in \mathrm{R}^{3}$, formed by $m$ identical grid sites defined as voxels, is defined as the simulation domain. Each site is identified by its centroid $x_{i} \in \mathrm{R}^{3}$ and it is labelled by an integer number, $\sigma\left(x_{i}\right) \in \mathrm{N}$, which can be interpreted as a degenerate spin originally coming from statistical physics. The neighbours of a lattice site $x_{i}$ are identified by $x_{i}^{\prime}$. Subdomains with identical label $\sigma$ form discrete objects, with an associated type $\tau$ : $\tau=M$ stands for medium, $\tau=S$ for the substrate, and $\tau=C$ stands for cells. Cell dynamics is obtained through an iterative and stochastic reduction of the overall energy, given by a Hamiltonian function $\mathrm{H}$. The employed algorithm is a modification of the Metropolis method (Metropolis et al., 1953) for Monte Carlo-Boltzmann dynamics (Deshpande et al., 1988). At each Monte Carlo Step (MCS), the model considers the motion of a source site $x$ to another neighbour lattice site $x^{\prime}$. Thus, we obtained two states: (1) the state before the spin copy where the site $x$ (that we will call $\mathrm{x}$ ) has not changed yet with an overall energy $\mathrm{H}_{\text {before spin copy }}$ and (2) the state after the spin copy where the site $x$ (that we will call $x^{\prime}$ ) has changed to the value of $x^{\prime}$ with

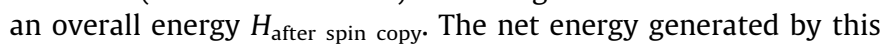
motion is calculated as:

$\left.\Delta H\right|_{\sigma(x) \rightarrow \sigma\left(x^{\prime}\right)}=H_{\text {afterspincopy }}-H_{\text {beforespincopy }}$

The trial spin update is validated by a Boltzmann-like probability function Pdefined as:

$\left.P\right|_{\sigma\left(x_{\text {source }}\right) \rightarrow \sigma\left(x_{\text {target }}\right)}=\min \left\{1, e^{-\frac{\Delta H}{T}}\right\}$

where $T$ is the Boltzmann temperature that has been interpreted as the fluctuation allowance of the environment. The Hamiltonian function $H$ is calculated as the sum of three intermediate Hamiltonian functions:

$H=H_{\text {adhesion }}+H_{\text {shape }}+H_{\text {externalpotential }}$

$H_{\text {adhesion }}$ describes the adhesion between the cell and the extracellular components (i.e. the medium or a given type of substrate), and it takes the following form:

$H_{\text {adhesion }}=\sum_{\left(x, x^{\prime}\right)} J_{\tau(\sigma(x)), \tau\left(\sigma\left(x^{\prime}\right)\right)} \cdot\left[1-\delta_{\tau(\sigma(x)), \tau\left(\sigma\left(x^{\prime}\right)\right)}\right]$

With $\delta_{\tau(\sigma(x)), \tau\left(\sigma\left(x^{\prime}\right)\right)}$ the Kronocher function equal to 1 if the sites $x$ and $\mathrm{x}$ ' belong to the same type of subdomain, and equal to 0 otherwise. $J_{\tau(\sigma(x)), \tau\left(\sigma\left(x^{\prime}\right)\right)}$ defines constant and homogenous binding forces per unit area between the cell and its environment. Then, it can assume different values according to the component the cell interacts with: 
- $J_{c m}$ characterizes the adhesion strength between the cell and the collagenous medium, composed by a mixture of soluble adhesion ligand and water solvent;

- J $J_{c s}$ characterizes the adhesive strength between the cell and the substrate.

$H_{\text {shape }}$ represents the morphological characteristics of each cell and it is constituted by a volume and a surface term, both defined as elastic potential as follows:

$H_{\text {shape }}=\lambda_{\text {surface }} \cdot\left(S-S_{c}\right)^{2}+\lambda_{\text {volume }} \cdot\left(V-V_{c}\right)^{2}$

With $S$ and $V$ the actual surface and volume of the cell, respectively and $S_{C}$ and $V_{c}$ the target surface and volume of the cell in the initial resting condition, respectively. $\lambda_{\text {surface }}$ and $\lambda_{\text {volume }}$ are two mechanical moduli. The former represents the deformability of the cell and it depends on the underneath substrate. The latter is set $\gg 1$ in order to keep a constant volume during the migration.

An energy term of migration $H_{\text {external potential }}$ is added in order to trigger the cell motility on the surface. $H_{\text {external potential }}$ reads

$H_{\text {externalpotential }}=-\vec{v} \cdot \overrightarrow{\delta r}$

where $\vec{v}$ is the external potential which defines the direction of migration (here it coincides with the direction $\mathrm{X}$ ) and $\overrightarrow{\delta r}$ is the displacement vector of the centre of mass (COM) of the cell generated by the spin copy.

\subsection{Configuration of the $C P$ model}

The lattice domain is a $400 \mu \mathrm{m} \times 240 \mu \mathrm{m} \times 80 \mu \mathrm{m}$ regular rectangular parallelepiped with no-flux boundary conditions along the four sides. Each lattice site $x_{i}$ is a $1 \mu \mathrm{m} \times 1 \mu \mathrm{m} \times 1 \mu \mathrm{m}$ voxel cube and a cell is initially represented by a hemisphere of radius $20 \mu \mathrm{m}$. The initial volume and surface of the cell are set to $8000 \mu \mathrm{m}^{3}$ and $5000 \mu \mathrm{m}^{2}$ respectively in order to respect the scale of $1 \mu \mathrm{m}^{2}$ per pixel. The temperature $T$ is set to $15 \times 10^{-27} \mathrm{~kg} /$ $\mathrm{m}^{2} \mathrm{~s}^{2}$. The coefficients $J_{\mathrm{cm}}$ and $J_{c s}$ have been set to $15 \times 10^{-15} \mathrm{~kg} /$ $\mathrm{s}^{2}$ and $1 \times 10^{-15} \mathrm{~kg} / \mathrm{s}^{2}$ respectively, in order to have the cell adapt to the morphology of the surface (Scianna et al., 2013). In order to have a cell that keeps a constant volume and surface and maintains enough elasticity to be able to move, $\lambda_{\text {surface }}$ and $\lambda_{\text {volume }}$ are fixed to $15 \times 10^{-3} \mathrm{~kg} / \mathrm{s}^{2} \mathrm{~m}^{2}$ and $50 \times 10^{-9} \mathrm{~kg} / \mathrm{s}^{2} \mathrm{~m}^{3}$ respectively. A MCS is set to $10 \mathrm{~s}$ and the simulations cover $8500 \mathrm{MCS}$, which corresponds to $24 \mathrm{~h}$. The substrate is divided in 3 different rectangular domains of $400 \mu \mathrm{m} \times 80 \mu \mathrm{m}$, each one describing a specific surface topography. For each configuration, the cell is initially seeded on the surface in resting position for $150 \mathrm{MCS}$, then it starts moving in the direction $v$ (imposed by $H_{\text {externalpotential }}$ ). To be able to visualize the migratory behaviour of the cell, we had to add a term of external potential, as it was described by the equation (6). It is an artificial term included in the Hamiltonian that we apply to the cell to sustain its motion across the substrate. If we look at the experimental studies, cell motions were usually created by microchannel (Ilina et al., 2011) or gradient of chemical substances (chemotaxis), with the motion sustained by the internal dynamics of the cell. However, our model is unable to reproduce such internal dynamics. Thus, the external dynamics was created and evaluated to obtain the minimum magnitude necessary to move the cell. Contrary to the model used by Allena et al. (2016) where the external potential is applied directly to the site, here the external potential is applied to the COM of the cell. However, at each step, the COM displacement is infinitesimal. So, we set a high value of $\|v\|$ at $10 \times 10^{-18}$ $\mathrm{kg} / \mathrm{s}^{2} \mathrm{~m}^{2}$. All the simulations are run 10 times in order to obtain consistent and reproducible data, and the average and deviation of the results are evaluated. Statistics were realized by a KruskalWallis test followed by a Pearson correlation test, with a level of significance set at a correlation $c=0.9$ and $p=0.05$. All the $\mathrm{CP}$ model parameters are listed in Table 1.

The simulations were performed on the open source package CompuCell3D (Swat et al., 2012). In particular, a Python script was developed to specify cell characteristics and import surface setting into the model.

\subsection{Description of the substrate roughness}

In order to analyse the influence of the surface roughness on cell motility, four different set of surfaces were numerically created:

1. The first set (Fig. 1a) is constituted by a surface whose roughness randomly varies in space. Then, the altitude $\mathrm{Z}(x, y)$, with $\mathrm{x}$ and $y$ the coordinates of each point on the surface, is defined as:

$Z(x, y)=Z_{0}+\operatorname{randi}(R)-R$

where $Z_{0}$ is the reference altitude, and $\operatorname{randi}(R)$ is a function which generates an integer between 0 and $R$, which is the maximum value assumed for the roughness.

2. The second and third sets (Fig. 1 b and c) are constituted by a surface whose roughness is represented by rectangular grooves of different width $w$, depth $d$, and orientation parallel (Fig. 1b and equation (8)) or perpendicular (Fig. 1c and equation (9)) with respect to the direction of motility $\mathrm{v}$. The altitude $Z(x, y)$ of each point on the surface is defined as follows:

$Z(x, y)=\left\{\begin{array}{c}Z_{0} \text { if } \bmod (y, w) \leq \frac{w}{2} \\ Z_{0}-d \text { else }\end{array}\right.$

$Z(x, y)=\left\{\begin{array}{c}Z_{0} \text { if } \bmod (x, w) \leq \frac{w}{2} \\ Z_{0}-d \text { else }\end{array}\right.$

where $\bmod ($.$) is the modulo operator.$

3. The fourth set (Fig. 1d) is constituted by a surface whose roughness is represented by sinusoidal grooves with different wavelength $\lambda$ and amplitude $A$ in the direction of motility v. The altitude $Z(x, y)$ reads:

$Z(x, y)=Z_{0}+\frac{A}{2} \cdot \cos \left(\frac{2 \cdot \pi \cdot y}{\lambda}\right)$

Some of the parameters previously introduced have been normalised with respect to the cell diameter $D$, as followed: $R^{*}=\frac{R}{D}$, $w^{*}=\frac{w}{D}, d^{*}=\frac{d}{D}, \lambda^{*}=\frac{\lambda}{D}$, and $A^{*}=\frac{A}{D}$. All the parameters are listed in Table 2 .

For each surface, we compute the roughness ratio parameter $r_{c}$, which is expressed as the ratio between the area of the surface with roughness and the area of the surface without roughness. For a smooth surface, $r_{c}=1$. The values of $r_{c}$ for each surface are listed in the Table 3-5 from Appendix A.1.

Table 1

CP model parameters.

\begin{tabular}{|c|c|c|c|}
\hline Description & Variable name & Value & Unit \\
\hline Step & $t$ & 8500 & MCS \\
\hline Temperature & $T$ & $15 \times 10^{-27}$ & $\mathrm{~kg} \mathrm{~m}^{2} / \mathrm{s}^{2}$ \\
\hline Lattice Domain & $\Omega$ & $400 \times 240 \times 80$ & $\mu \mathrm{m}$ \\
\hline Target cell volume & $V_{c}$ & $8 \times 10^{3}$ & $\mu \mathrm{m}^{3}$ \\
\hline Target cell surface & $S_{c}$ & $5 \times 10^{3}$ & $\mu \mathrm{m}^{2}$ \\
\hline Lambda volume & $\lambda_{\text {volume }}$ & $50 \times 10^{-9}$ & $\mathrm{~kg} / \mathrm{s}^{2} \mathrm{~m}^{3}$ \\
\hline Lambda surface & $\lambda_{\text {surface }}$ & $15 \times 10^{-3}$ & $\mathrm{~kg} / \mathrm{s}^{2} \mathrm{~m}^{2}$ \\
\hline Adhesion cell/medium & $J_{c m}$ & $15 \times 10^{-15}$ & $\mathrm{~kg} / \mathrm{s}^{2}$ \\
\hline Adhesion cell/substrate & $J_{C S}$ & $1 \times 10^{-15}$ & $\mathrm{~kg} / \mathrm{s}^{2}$ \\
\hline External potential $v$ & $v$ & {$\left[\begin{array}{c}-10 \times 10^{-18} \\
0 \\
0\end{array}\right]$} & $\mathrm{kg} / \mathrm{s}^{2} \mathrm{~m}^{3}$ \\
\hline
\end{tabular}




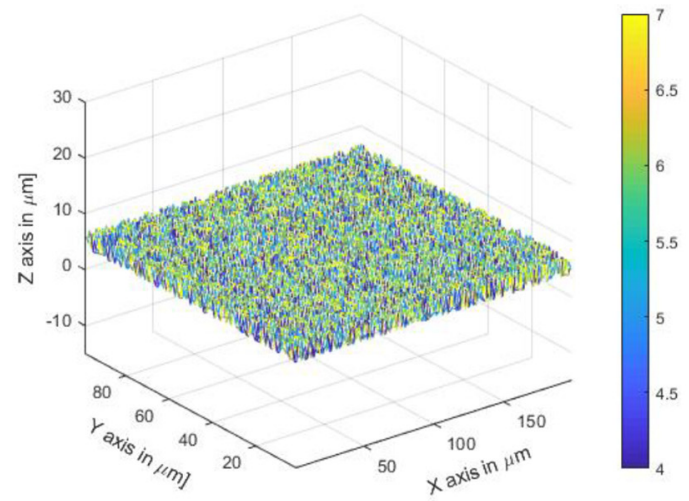

(a) Random roughness for $R=3 \mu \mathrm{m}$

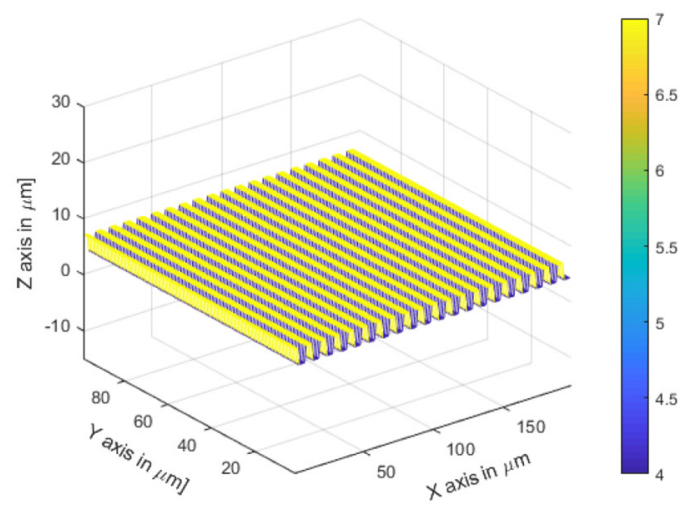

(c) Rectangular perpendicular grooves structure with a depth $d=3 \mu \mathrm{m}$ and $a$ width $w=10 \mu \mathrm{m}$

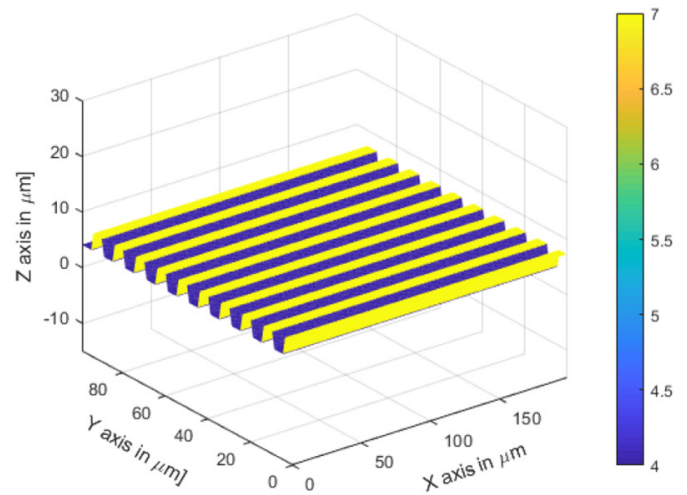

(b) Rectangular parallel grooves structure with a depth $d=5 \mu \mathrm{m}$ and $a$ width $w=10 \mu \mathrm{m}$

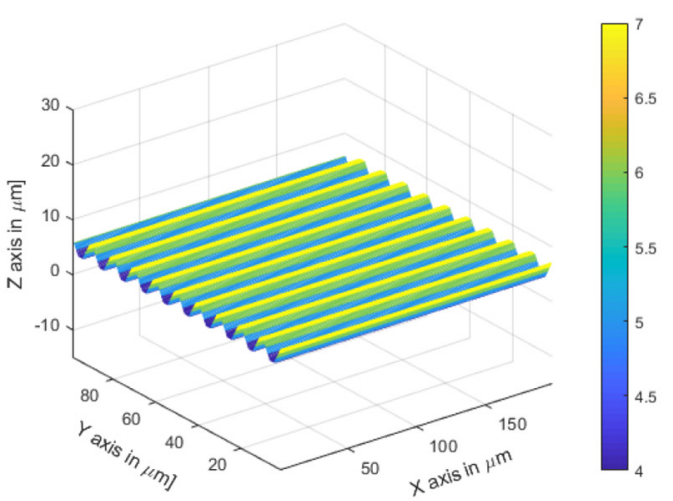

(d) Sinusoidal parallel grooves with a amplitude $A=5 \mu \mathrm{m}$ and a wavelength $\lambda=10 \mu \mathrm{m}$

Fig. 1. 3D surface topography for each set of surfaces. The colorbar indicates the range of the z position of the surface.

Table 2

Input surface parameters.

\begin{tabular}{llll}
\hline Description & $\begin{array}{l}\text { Variable } \\
\text { name }\end{array}$ & Values & Units \\
& $Z_{0}$ & 20 & $\mu \mathrm{m}$ \\
Reference altitude & $D$ & 20 & $\mu \mathrm{m}$ \\
Cell diameter & $R$ & {$[0-10]$} & $\mu \mathrm{m}$ \\
Random roughness range & $w$ & $5,10,20$ & $\mu \mathrm{m}$ \\
Groove width & $d$ & $1,3,5$ & $\mu \mathrm{m}$ \\
Groove depth & $\lambda$ & $5,10,20$ & $\mu \mathrm{m}$ \\
Sinusoidal pattern & & & \\
$\quad$ wavelength & $A$ & $2,3,4,5,6,8,10,15,20$ & $\mu \mathrm{m}$ \\
Sinusoidal pattern & & & \\
$\quad$ amplitude & $R^{*}$ & {$[0-0.5]$} & - \\
Normalised random & & & - \\
$\quad$ roughness range & $w^{*}$ & $0.25,0.5,1$ & - \\
$\quad$ Normalised width & $d^{*}$ & $0.05,0.15,0.25$ & - \\
$\quad$ Normalised depth & $\lambda^{*}$ & $0.25,0.5,1$ & - \\
$\quad$ Normalised wavelength & $A^{*}$ & $0.1,0.15,0.2,0.25,0.3,0.4$, & - \\
$\quad$ Normalised amplitude & & $0.5,0.75,1$ & \\
& & & \\
\hline
\end{tabular}

In the next section we will present the results of our simulations. More particularly we have evaluated the output parameters of the model, i.e. the cell speed, the contact surface and the cell shape, as function of specific input parameters $\left(J_{C S}, R^{*}, w^{*}, d^{*}, \lambda^{*}\right.$ and $A^{*}$ ) according to the set of simulations.
Table 3

Value of $r_{c}$ for random rough surfaces.

\begin{tabular}{ll}
\hline $\boldsymbol{R}^{*}$ & $\boldsymbol{r}_{\boldsymbol{c}}$ \\
\hline 0 & 1 \\
0,05 & 1,4 \\
0,1 & 1.8 \\
0,15 & 2.3 \\
0,2 & 2.8 \\
0,25 & 3.3 \\
0,3 & 3.8 \\
0,35 & 4.3 \\
0,4 & 4.8 \\
0,45 & 5.3 \\
0,5 & 5.8 \\
\hline
\end{tabular}

\section{Results and discussion}

\subsection{Cell migration on substrate with random roughness}

3.1.1. Smooth VS rough surface

In the first set of simulations, we analyse the influence of the roughness, which randomly varies over the substrate, on cell motility. Fig. 2 shows the cell at the resting position on smooth 
Table 4

Value of $r_{c}$ for the rectangular grooves.

\begin{tabular}{|c|c|c|c|c|c|}
\hline \multirow[t]{2}{*}{$d^{*}$} & \multicolumn{2}{|l|}{$\underline{\boldsymbol{r}_{c}}$} & \multirow[t]{2}{*}{$\boldsymbol{w}^{*}$} & \multicolumn{2}{|l|}{$\underline{r_{c}}$} \\
\hline & $w^{*}=0,5$ & $w^{*}=1$ & & $d^{*}=0,15$ & $d^{*}=0,25$ \\
\hline 0,05 & 1,08 & 1,04 & 0,2 & 2,09 & 3,06 \\
\hline 0,1 & 1,25 & 1,12 & 0,3 & 1,72 & 2,37 \\
\hline 0,15 & 1,43 & 1,22 & 0,4 & 1,54 & 2,03 \\
\hline 0,2 & 1,63 & 1,31 & 0,5 & 1,43 & 1,82 \\
\hline 0,25 & 1,82 & 1,41 & 0,6 & 1,36 & 1,69 \\
\hline 0,3 & 2,02 & 1,51 & 0,7 & 1,31 & 1,58 \\
\hline 0,35 & 2,22 & 1,61 & 0,8 & 1,27 & 1,51 \\
\hline 0,4 & 2,42 & 1,71 & 0,9 & 1,24 & 1,45 \\
\hline 0,45 & 2,62 & 1,81 & 1 & 1,22 & 1,41 \\
\hline 0,5 & 2,82 & 1,91 & 1,1 & 1,19 & 1,36 \\
\hline 0,55 & 3,02 & 2,01 & 1,2 & 1,18 & 1,34 \\
\hline 0,6 & 3,22 & 2,11 & 1,3 & 1,16 & 1,31 \\
\hline 0,65 & 3,42 & 2,21 & 1,4 & 1,15 & 1,29 \\
\hline 0,7 & 3,62 & 2,31 & 1,5 & 1,14 & 1,27 \\
\hline 0,75 & 3,82 & 2,41 & 1,6 & 1,14 & 1,26 \\
\hline
\end{tabular}

Table 5

Value of $r_{c}$ for the sinusoidal grooves.

\begin{tabular}{|c|c|c|c|c|c|}
\hline \multirow[t]{2}{*}{$A^{*}$} & \multicolumn{2}{|l|}{$\boldsymbol{r}_{c}$} & \multirow[t]{2}{*}{$\lambda^{*}$} & \multicolumn{2}{|l|}{$\boldsymbol{r}_{\boldsymbol{c}}$} \\
\hline & $\lambda^{*}=0,5$ & $\lambda^{*}=1$ & & $A^{*}=0,15$ & $A^{*}=0,25$ \\
\hline 0,1 & 1,08 & 1,04 & 0,2 & 1,82 & 2,70 \\
\hline 0,15 & 1,17 & 1,08 & 0,3 & 1,55 & 1,96 \\
\hline 0,2 & 1,25 & 1,12 & 0,4 & 1,31 & 1,72 \\
\hline 0,25 & 1,41 & 1,17 & 0,5 & 1,25 & 1,50 \\
\hline 0,3 & 1,50 & 1,21 & 0,6 & 1,21 & 1,34 \\
\hline 0,35 & 1,58 & 1,25 & 0,7 & 1,18 & 1,35 \\
\hline 0,4 & 1,83 & 1,29 & 0,8 & 1,15 & 1,26 \\
\hline 0,45 & 1,91 & 1,33 & 0,9 & 1,14 & 1,23 \\
\hline 0,5 & 2,20 & 1,45 & 1 & 1,12 & 1,21 \\
\hline 0,55 & 2,29 & 1,50 & 1,1 & 1,11 & 1,19 \\
\hline 0,6 & 2,45 & 1,54 & 1,2 & 1,10 & 1,17 \\
\hline 0,65 & 2,66 & 1,66 & 1,3 & 1,10 & 1,16 \\
\hline 0,7 & 2,82 & 1,70 & 1,4 & 1,09 & 1,15 \\
\hline 0,75 & 3,05 & 1,83 & 1,5 & 1,08 & 1,14 \\
\hline 0,8 & 3,21 & 1,87 & 1,6 & 1,08 & 1,13 \\
\hline
\end{tabular}

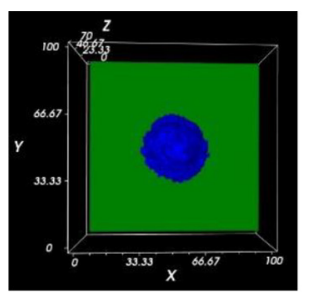

(a) $(X-Y)$ view of cell on smooth surface $\left(R^{*}=0\right)$

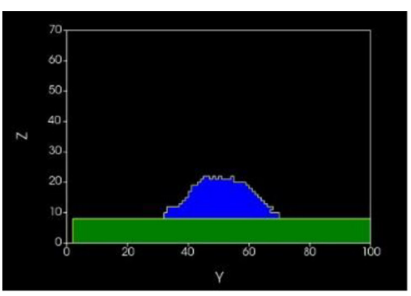

(b) $(Y-Z)$ view of cell on smooth surface $\left(R^{*}=0\right)$

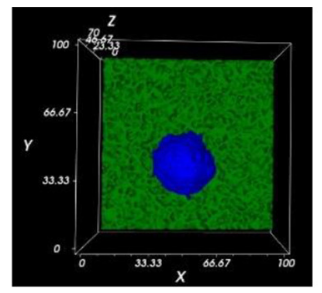

(c) $(X-Y)$ view of the cell on random rough surface $\left(R^{*}=0.25\right)$

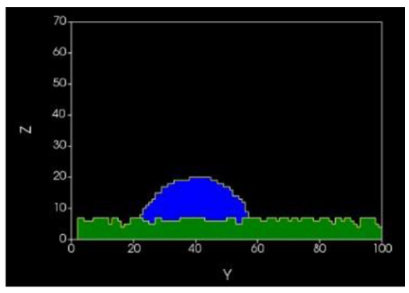

(d) $(Y-Z)$ view of the cell on random rough surface

$\left(R^{*}=0.25\right)$

Fig. 2. Shape of the cell at the resting position on smooth $\left(R^{*}=0\right)(\mathrm{a}-\mathrm{b})$ and rough $\left(R^{*}=0.25\right)(\mathrm{c}-\mathrm{d})$ surfaces in the $(\mathrm{X}-\mathrm{Y})$ and $(\mathrm{Y}-\mathrm{Z})$ planes.

$\left(R^{*}=0\right)$ (Fig. 2a and b) and random roughness $\left(R^{*}>0\right)$ (Fig. $2 \mathrm{c}$ and $\mathrm{d}$ ) surfaces.

Fig. 2a and b show that the cell acquires naturally a hemispherical shape with a circular contact surface, which is maintained during the migration (see Movie S1). Such a shape, which has been experimentally observed (Lo et al., 2000; Rosales-Leal, 2010), is due to the cell trying to minimise its energy and results in the equilibrium between the internal dynamics of the cell and the environment.

Fig. 3 presents the evolution of the cell migration on smooth surface $\left(R^{*}=0\right)$ in terms of trajectories (Fig. 3a), contact surface (Fig. 3b) and cell elongation $\frac{a}{c}$ (Fig. 3c). The cell follows a linear trajectory (Fig. 3a) in the direction X of the external potential. A tran- sitory phase is observed for the contact surface (Fig. 3b), with an increase up to $940 \mu \mathrm{m}^{2}( \pm 10)$ that stabilises around 2000 MCS. The same phenomenon takes place for the cell elongation parameter (Fig. 3c), with a stabilisation around $\frac{a}{c}=2$ at 5000 MCS. This transitory phase could represent the period during which the cell adapts itself to its environment. Some small variations are observed between each simulation, with no significant differences.

On a random rough surface $\left(R^{*}=0.25\right)$, there is no significant difference in terms of shape at the resting position compared to the smooth surface (Fig. 2c and d). However, differences are found during the cell migration. The analysis of the cell trajectory on a random rough surface (Fig. 4a) shows that the cell remains aligned with the direction of the external potential (i.e. the $\mathrm{X}$ direction). 


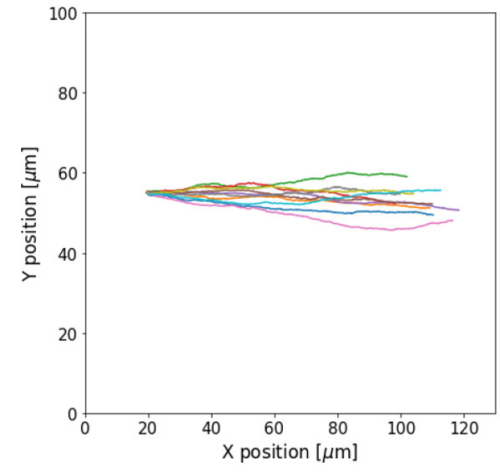

(a) Cell trajectories in the $(X-Y)$ plane

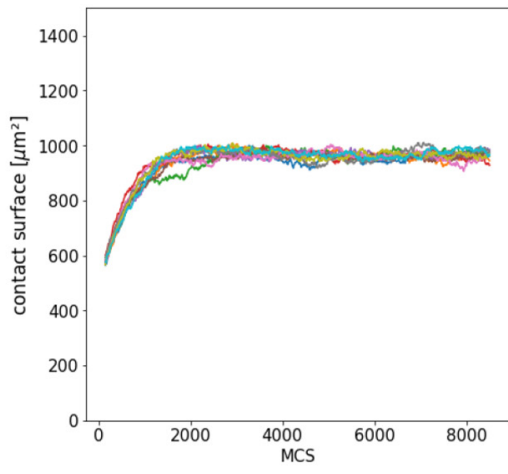

(b) Evolution of the contact surface

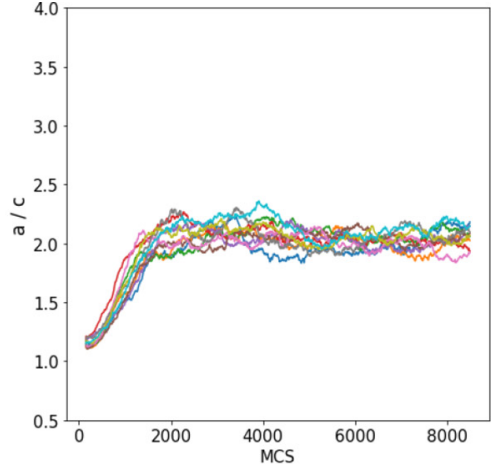

(c) Evolution of $\frac{a}{c}$

Fig. 3. Simulation of cell migration over a smooth surface $\left(R^{*}=0\right)$. Each figure displays the results of ten simulations.

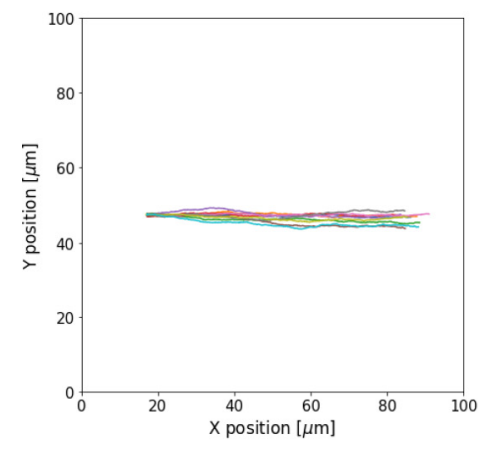

(a) Cell trajectories in the $(X-Y)$ plane

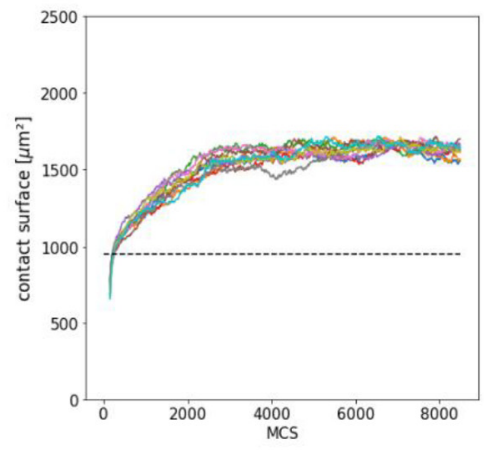

(b) Evolution of the contact surface.

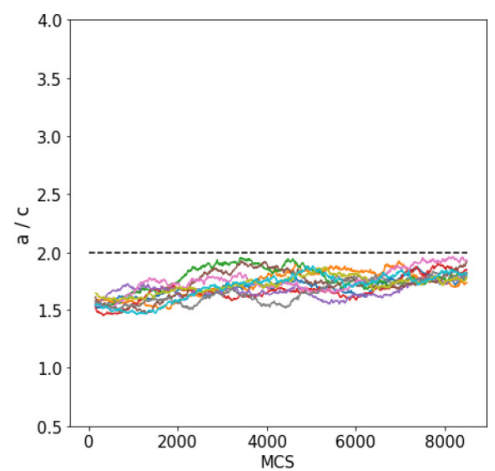

(c) Evolution of $\frac{a}{c}$

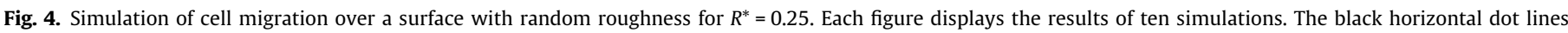
represent the average value of the specific parameter for the simulations on the smooth surface.

In terms of contact surface, we observe an increase up to $1620 \mu \mathrm{m}^{2}$ at 8500 MCS, with a stabilization between 2000 and 3000 MCS (Fig. 4b). Such a value is almost double compared to that found on the smooth surface and could be the result of the roughness. In terms of elongation, Movie S2 and Fig. 4c show a reduction of the parameter $\frac{\mathrm{a}}{\mathrm{c}}$ compared to the smooth surface. In fact, one can notice that, during the migration, the cell exhibits a smaller elliptic shape compared to the migration on the smooth surface, which may be due to a higher energy necessary to the cell to move on a rough surface.

Fig. 5 presents the results of the cell migration on random rough surfaces for different values of $R^{*}$. A decrease in cell speed is registered as the parameter $R^{*}$ increases, from $8.9 \mu \mathrm{m} / \mathrm{h}( \pm 0.33)$ for the smooth surface $\left(R^{*}=0\right)$ up to $1.61 \mu \mathrm{m} / \mathrm{h}( \pm 0.16)$ for $R^{*}=0.5$ (Fig. $5 \mathrm{a}$ ). In terms of shape (Fig. $5 \mathrm{c}$ ), the simulations confirm that the cell acquires a smaller elliptic shape compared to the migration on the smooth surface. Concerning the roughness of the surface (Table 3 from Appendix A.1), an increase of the roughness ratio $r_{c}$ from 1 at $R^{*}=0$ to 5.8 at $R^{*}=0.5$ is observed, followed by an increase of the contact surface from $940 \mu \mathrm{m}^{2}( \pm 10)$ to $1981 \mu \mathrm{m}^{2}$ $( \pm 17)$ (Fig. 5b). According to these results, we can point out a direct correlation between $r_{c}$ and the contact surface $(c=1, \mathrm{p} \ll 0.05)$, confirming the hypothesis that an increase of the roughness leads to an increase of the contact surface. A statistical analysis presents a negative correlation between the evolution of the cell speed and the contact surface ( $c=-0.91$ and $p=0.029$ ). The results of
Fig. 5c support this idea, with a decrease of the cell elongation with the increase of $R^{*}$, from 2 at $R^{*}=0$ to 1.26 at $R^{*}=0.5$. One can notice that the cell spend more energy to be able to move on the rough surface, due to the barrier created by random elevations. These results can be compared to the study of Han et al (Han et al., 2015), where they showed a decrease of the cell speed and of the adhesion strength on smooth surfaces with added nanoroughness, compared to the smooth surface itself. Nonetheless, they did not evaluate the correlation between the two aforementioned quantities.

\subsubsection{Analysis of $J_{c S} V S R^{*}$}

Next, we wanted to quantify the influence of $J_{c s}$ and $R^{*}$ on the CP output parameters. To do so, we ran the same simulations as previously for different values of the adhesion energy $J_{c S}$ and random roughness parameter $R^{*}$. More specifically, $J_{c s}$ randomly varied between $1.10^{-15}$ and $25.10^{-15} \mathrm{~kg} / \mathrm{s}^{2}$ and $R^{*}$ is equal to $0,0.15$, and 0.25 . It has to be recalled that the higher $J_{c s}$, the lower the adhesion of the cell to the surface.

Fig. 6a presents the evolution of the cell speed as function of $J_{c s}$ and $R^{*}$. For $R^{*}=0$, the cell speed decreases as $J_{c S}$ increases, from over $8 \mu \mathrm{m} / \mathrm{h}$ down to $2.5 \mu \mathrm{m} / \mathrm{h}$ for $J_{c S}=15.10^{-15} \mathrm{~kg} / \mathrm{s}^{2}$, where it stabilises. For $R^{*}=0.15$, an increase of the cell speed is observed as $J_{c s}$ increases, up to a maximum value around $4.5 \mu \mathrm{m} / \mathrm{h}$ for $J_{c S}=5.10^{-15} \mathrm{~kg} / \mathrm{s}^{2}$, followed by a decrease down to around $2.5 \mu \mathrm{m} / \mathrm{h}$ where it stabilises. Similarly, for $R^{*}=0.25$, an increase of the cell 


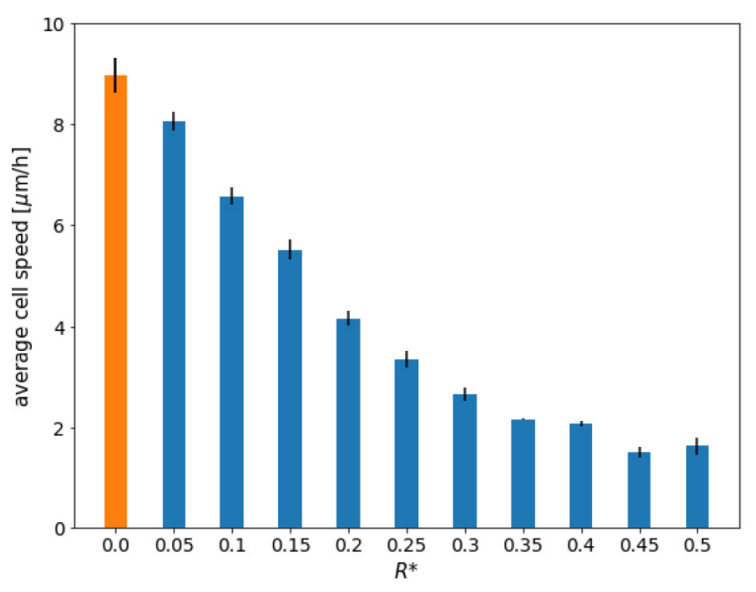

(a) Evolution of the average cell speed as a function of $R^{*}$.

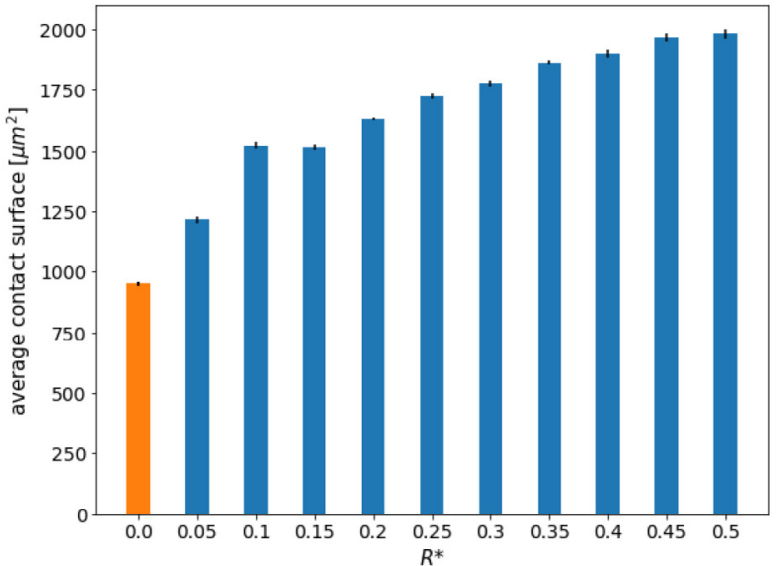

(b) Evolution of the average contact surface as a function of $R^{*}$.

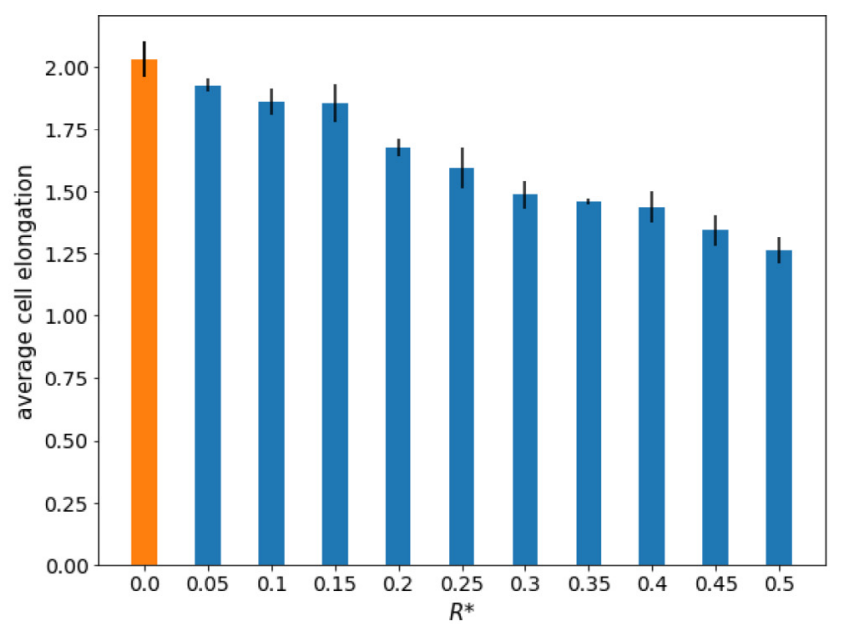

(c) Evolution of the average cell elongation $\left(\frac{a}{c}\right)$ as a function of $R^{*}$.

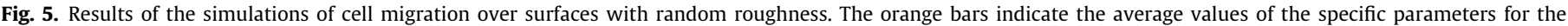
simulations on the smooth surface. (For interpretation of the references to colour in this figure legend, the reader is referred to the web version of this article.)

speed is registered as $J_{c s}$ increases, up to a maximum value around $3.3 \mu \mathrm{m} / \mathrm{h}$ at $J_{c s}=10.10^{-15} \mathrm{~kg} / \mathrm{s}^{2}$, followed by a decrease down to around $2.5 \mu \mathrm{m} / \mathrm{h}$ where it starts to be constant. In terms of contact surfaces (Fig. 6b), we confirm a decrease as $J_{c s}$ increases, regardless the value of $R^{*}$. Besides, the contact surface decreases with the increase of $R^{*}$. Regardless the initial value of the contact surface for each $R^{*}$, the minimum value (around $360 \mu \mathrm{m}^{2}$ ) is obtained at $J_{c s}=25.10^{-15} \mathrm{~kg} / \mathrm{s}^{2}$. Concerning the cell elongation (Fig. $6 \mathrm{c}$ ), similarly to the contact surface, a decrease is registered as $J_{c s}$ increases, regardless the value of $R^{*}$. The maximum value of cell elongation is 2 for $R^{*}=0$ and $J_{c s}=1.10^{-15} \mathrm{~kg} / \mathrm{s}^{2}$, whereas the minimum value is around 1.1 for $R^{*}=0.15$ and 0.25 , and $J_{c s}=25.10^{-15} \mathrm{~kg} / \mathrm{s}^{2}$. According to these results, we can conclude that an increase of the adhesion strength (i.e. a decrease of $J_{c S}$ ) triggers an increase of the cell speed in all the cases whereas a geometrical increase of the adhesion surface (i.e. an increase of $r_{c}$ ) leads to a decrease of the cell speed. Thus, on smooth surfaces the cell slides with no change of the overall energy, whereas on rough surfaces $\left(R^{*}>0\right)$, the motility of the cell is inhibited with an increase of the overall energy. Besides, the results confirm that the influence of $\mathrm{R}^{*}$ depends on $J_{c s}$. Indeed, the increase of the cell speed as $J_{c s}$ increases (i.e. the adhesion strength of the surface decreases) observed for $R^{*}>0$, combined with the decrease of the contact surface, shows a decrease of the inhibitor effect of the surface due to the cell decreasing the contact surface. However, beyond a specific value of $J_{c s}$ (around $5.10^{-15} \mathrm{~kg}$ / $\mathrm{s}^{2}$ for $R^{*}=0.15$ and around $10.10^{-15} \mathrm{~kg} / \mathrm{s}^{2}$ for $\left.R^{*}=0.25\right)$, the adhesion to the surface is too low to promote the migration, thus the cell speed goes down until $J_{c s}$ is equal to $15.10^{-15} \mathrm{~kg} / \mathrm{s}^{2}$ (equal to $J_{c m}$ ). Thus, we can assume that the more the cell adheres to the surface, the more it is affected by its topography. Consequently, this suggests that the adhesion due to the wetting effects is predominant compared to the adhesion due to the geometrical effects, and it also shows that the parameter $J_{c S}$ can be used to modulate the contact surface between the cell and the substrate. Furthermore, knowing that the roughness affects the surface energy which in turn affects the cell adhesion by increasing it (Ponsonnet, et al., 2003; Ranella et al., 2010), we can assume that the main benefit of the roughness comes from the increase of the adhesion rather than the increase of the area between the cell and the substrate, explaining why roughness at nanoscale is prioritised.

\subsection{Cell migration on rectangular grooved substrate}

In this second set of the simulations, we analyse the influence of the topography of the surface (i.e. structure and orientation) on cell migration. The literature shows that the mere presence of a specific 


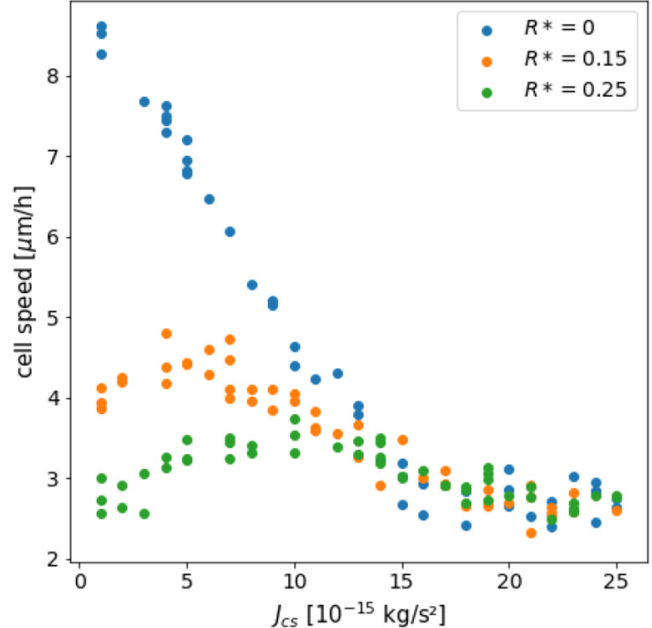

(a) Evolution of the average cell speed as function $J_{c s}$ for different values of $R^{*}$

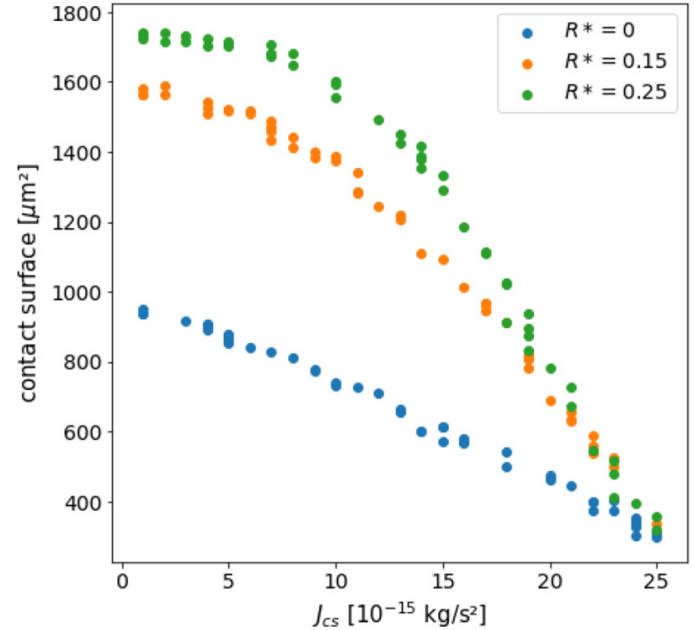

(b) Evolution of the average contact surface as function of $J_{c s}$ for different values of $R^{*}$

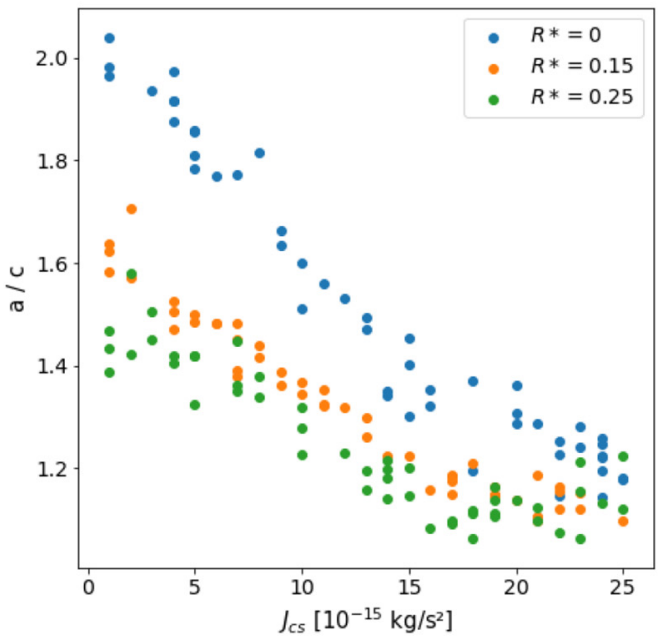

(c) Evolution of the average cell elongation $\left(\frac{a}{c}\right)$ as function of $J_{c s}$ for different values of $R^{*}$

Fig. 6. Results for the simulations of the cell migration over substrates with random roughness for various values of $J_{C S}$ and $R^{*}$.

periodic microstructure on the surface affects various cell mechanisms, such as the adhesion, the orientation, or the speed (Kaiser et al., 2006). Thus, we consider two surfaces with rectangular grooves that are i) parallel and ii) perpendicular to the direction of motion $v$ (i.e. the $\mathrm{X}$ direction). Each surface is defined by a normalised depth $d^{*}$ and a normalised width $w^{*}$ along the $\mathrm{Y}$ axis. The adhesion parameter $J_{c s}$ is fixed and equal to $1.10^{-15} \mathrm{~kg} / \mathrm{s}^{2}$.

\subsubsection{Rectangular parallel grooves}

Fig. 7 shows the shape acquired by the cell at the resting position on the surface with rectangular parallel grooves. Since no external potential is applied, the cell aligns itself with the grooves (Fig. 7a). Here again, we can assume that this specific shape is the result of the energy minimisation.

In terms of COM trajectories (Fig. 8a), the cell follows a straight line, which corresponds to the direction of the grooves. In terms of contact surface (Fig. 8b), we have an increase up to approximatively $1800 \mu \mathrm{m}^{2}$ around 2000 MCS when the cell starts aligning with the grooves. In terms of shape (Fig. 8c), a clear elongation of the cell in the $\mathrm{X}$ direction is observed, with the increase of the $\mathrm{X}$ component of $\frac{a}{c}$ up to 2.6 around 2000 MCS. Significant differences are observed for the cell elongation between each simulation which can be explained by the random adhesion to the adjacent grooves during the migration.

In order to analyse the influence of $w^{*}$ and $d^{*}$ on the cell migration, two separate studies are performed. The first one simulates the cell migration as a function of $d^{*}$ for two fixed values of $w^{*}$ (Fig. 9a:c). The second one simulates the cell migration as a function of $w^{*}$ for two fixed values of $d^{*}$ (Fig. 9d:f).

Fig. 9a shows the values of the cell speed for different values of the normalised depth $d^{*}$ at fixed width $w^{*}$, with the black line corresponding to the average cell speed on the smooth surface. For $w^{*}=0.5$, as $d^{*}$ increases from 0.05 to 0.25 , a general increase of the cell speed is registered from $11.1 \mu \mathrm{m} / \mathrm{h}( \pm 0.4)$ to $16 \mu \mathrm{m} / \mathrm{h}$ $( \pm 0.5)$. After attaining this maximum value, the cell speed decreases down to $6.9 \mu \mathrm{m} / \mathrm{h}( \pm 0.16)$ at $d^{*}=0.75$. In the case of 


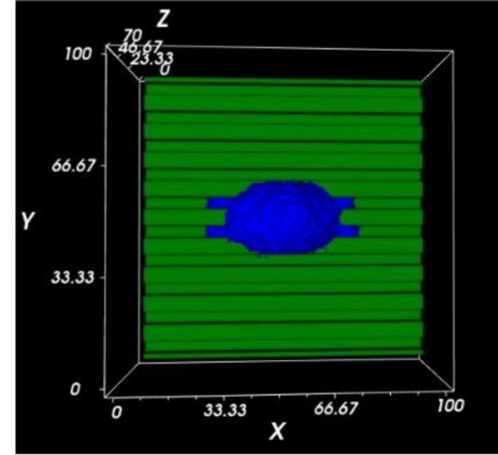

(a) $3 D$ view of the cell on rectangular grooves

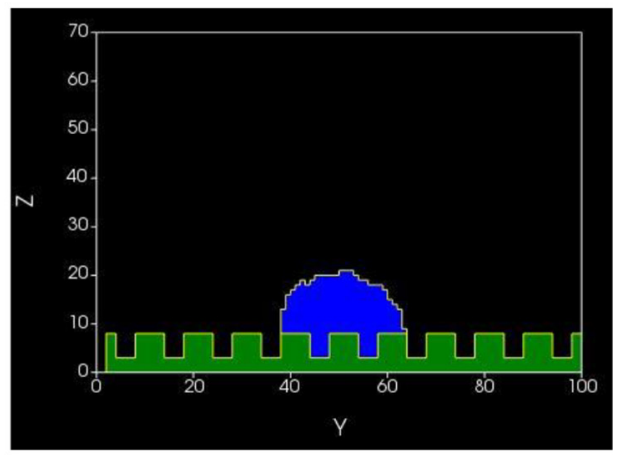

(b) $(X-Z)$ view of the cell on rectangular grooves

Fig. 7. Shape of the cell at the resting position on the surface with rectangular parallel grooves. Here, the grooves are defined by $w^{*}=0.5$ and $\mathrm{d}^{*}=0.25$.

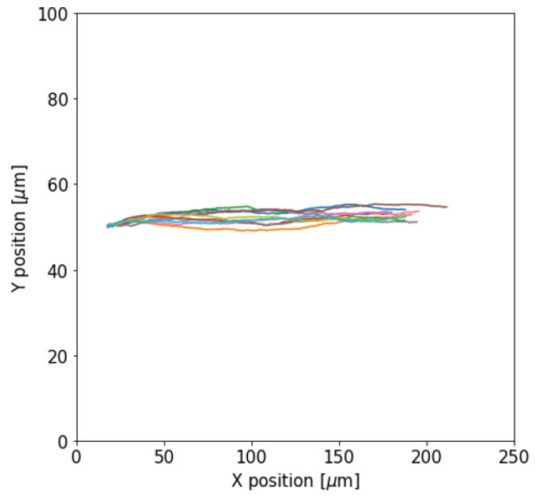

(a) Cell trajectories in the $(X-Y)$ plane

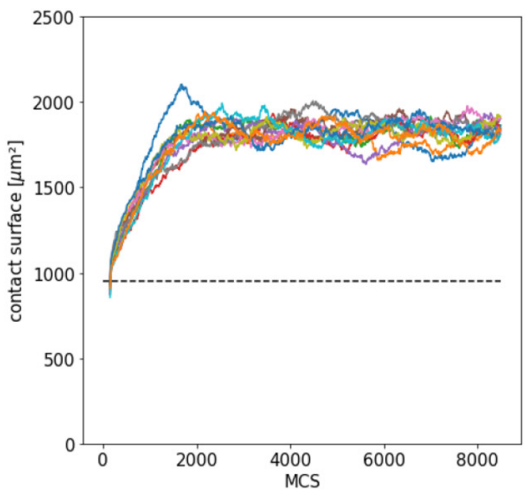

(b) Evolution of the contact surface.

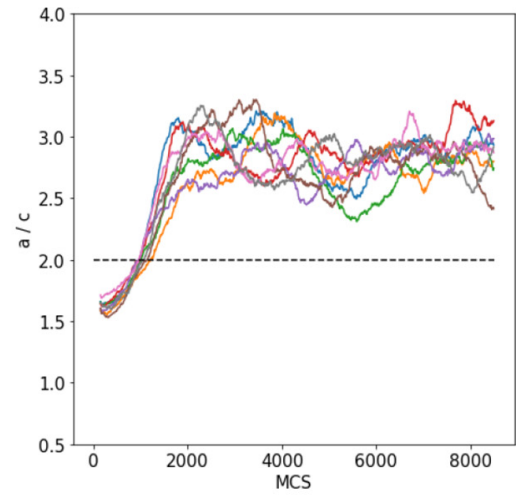

(c) Evolution of $\frac{a}{c}$.

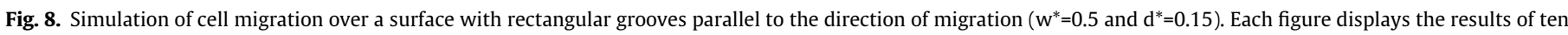
simulations. The black horizontal dot lines represent the average value of the specific parameter for the simulations on the smooth surface.

$w^{*}=1$, a general increase of the cell speed is observed from $11.4 \mu \mathrm{m} / \mathrm{h}( \pm 0.2)$ at $d^{*}=0.05$ to $15.7 \mu \mathrm{m} / \mathrm{h}( \pm 0.6)$ at $d^{*}=0.25$. Afterwards, the cell speed remains stable until $d^{*}=0.4$, and starts to decrease again down to $12.9 \mu \mathrm{m} / \mathrm{h}( \pm 0.56)$ at $d^{*}=0.75$. Therefore, the results show that the increase of the amplitude of the groove have for effect either to improve or inhibit the cell. In terms of cell shapes (see Movie S3), we notice an increase of the external envelope of the cell, with a clear elongation along the direction of the grooves, regardless their dimension. This is reflected by a general increase of the contact surface from $1482 \mu \mathrm{m}^{2}( \pm 27)$ at $d^{*}=0.05$ to $3115 \mu \mathrm{m}^{2}( \pm 11)$ at $d^{*}=0.75$ for $w^{*}=0.5$, and from $1371 \mu \mathrm{m}^{2}$ $( \pm 19)$ at $d^{*}=0.05$ to $1846 \mu \mathrm{m}^{2}( \pm 45)$ at $d^{*}=0.75$ for $w^{*}=1$ (Fig. $9 \mathrm{~b}$ ). These values are significantly higher than those found for migration on the smooth surface (Fig. 3b), regardless the values of $d^{*}$ and $w^{*}$. In addition, a direct correlation is found between the evolution of the contact surface and $r_{c}(\mathrm{r}=0.9, \mathrm{p} \ll 0.05)$ (Table 4 in Appendix A.1). In terms of cell elongations (Fig. 9c), the values obtained on rectangular parallel grooves are significantly higher than those obtained on the smooth surface. For $w^{*}=0.5$, we observe a small increase from $2.83( \pm 0.08)$ at $d^{*}=0.05$ to $3.12( \pm 0.07)$ at $d^{*}=0.15$. Then, a decrease is observed down to $2.4( \pm 0.05)$ at $d^{*}=0.6$. For $w^{*}=1$, we observe a small increase from $2.9( \pm 0.08)$ at $d^{*}=0.05$ to $3.03( \pm 0.07)$ at $d^{*}=0.15$. A new slight increase is found at $d^{*}=0.5$ up to $3.11( \pm 0.08)$ at $d^{*}=0.65$. No significant differences are found for $d^{*}=0.7$ and 0.75 . No significant relationship was found between the evolution of the cell speed and the cell elongation $(\mathrm{p}>0.05)$.
The evolution of the cell speed as a function of $w^{*}$ for $d^{*}=0.15$ and $d^{*}=1$ are reported in Fig. 9d. For $d^{*}=0.15$, the cell speed increases from $3.6 \mu \mathrm{m} / \mathrm{h}( \pm 0.4)$ at $w^{*}=0.2$ to $14.6 \mu \mathrm{m} / \mathrm{h}( \pm 0.7)$ at $w^{*}=0.5$, followed by a low decrease down to $11.9 \mu \mathrm{m} / \mathrm{h}( \pm 0.4)$ at $w^{*}=1.6$. The cell speed at $w^{*}=0.2$ is significantly lower than the cell speed on the smooth surface, showing that the cell has difficulty to move on the surface. For $d^{*}=0.25$, we observe an increase of the cell speed from $1.4 \mu \mathrm{m} / \mathrm{h}( \pm 0.3)$ at $w^{*}=0.2$ to $16.4 \mu \mathrm{m} / \mathrm{h}( \pm 0.3)$ at $w^{*}=0.9$. Then, the cell speed decreases down to $12.7 \mu \mathrm{m} / \mathrm{h}( \pm 0.9)$ at $w^{*}=1.6$. The cell speed at $w^{*}=0.2$ and 0.3 is significantly lower than the cell speed on the smooth surface. The evolution of the cell shape shows a decrease of the cell elongation as $w^{*}$ increases. This is reflected by a decrease of the contact surface as $w^{*}$ increases from 0.2 to 0.9 , regardless $d^{*}$ (Fig. 9e), from $2599 \mu \mathrm{m}^{2}( \pm 15)$ to $1390 \mu \mathrm{m}^{2}( \pm 9)$ for $d^{*}=0.15$, and from $2863 \mu \mathrm{m}^{2}( \pm 13)$ to $1571 \mu \mathrm{m}^{2}( \pm 14)$ for $d^{*}=0.25$. Beyond $w^{*}=1$, no significant differences are found for both $d^{*}=0.15$ and $d^{*}=0.25$. Compared to the smooth surface, the values of the contact surface are significant higher regardless $w^{*}$. A direct correlation between the evolution of the contact surface and $r_{c}$ is also observed in this case (Table 4 in Appendix A.1), for both values of $d^{*}(r=0.9, p \ll 0.05)$. In terms of cell elongation (Fig. 9f), for $d^{*}=0.15$, an increase is observed from $2.1( \pm 0.07)$ at $w^{*}=0.2$ to $3.08( \pm 0.1)$ at $w^{*}=0.3$, followed by a low decrease down to $2.24( \pm 0.04)$ at $w^{*}=1.6$. No significant differences are found between the cell elongation for $w^{*}=0.2$ and the case of the smooth surface. For $d^{*}=0.25$, we observe an increase of the cell elongation from $1.61( \pm 0.04)$ at $w^{*}=0.2$ to $2.91( \pm 0.09)$ at $w^{*}=0.8$. 


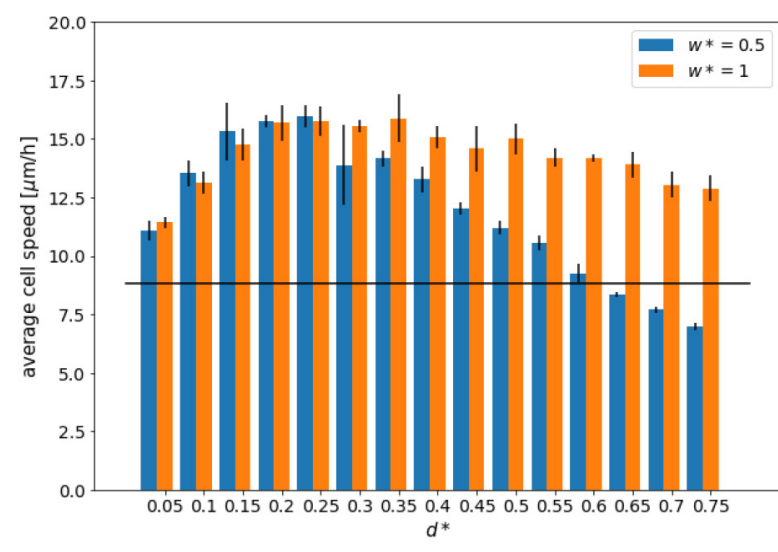

(a) Evolution of the average cell speed as a function of $d^{*}$ for $w^{*}=0.5$ (blue bars) and 1 (orange bars)

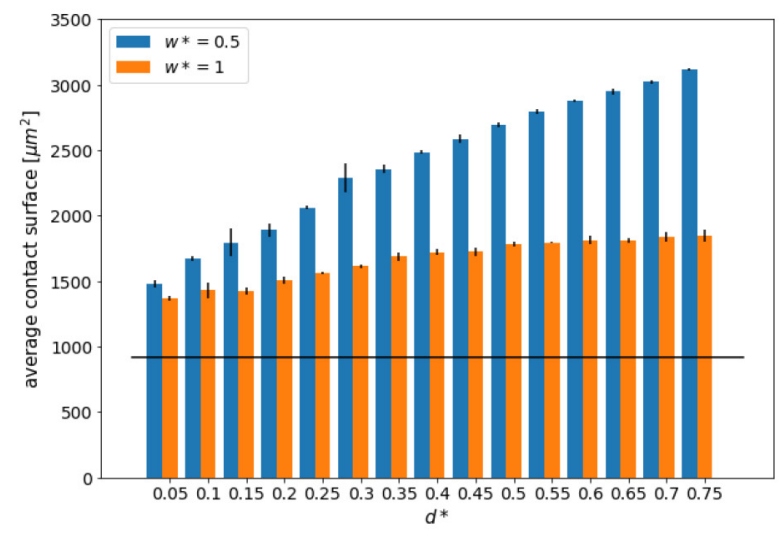

(b) Evolution of the average contact surface as a function of $d^{*}$ for $w^{*}=0.5$ (blue bars) and 1 (orange bars)

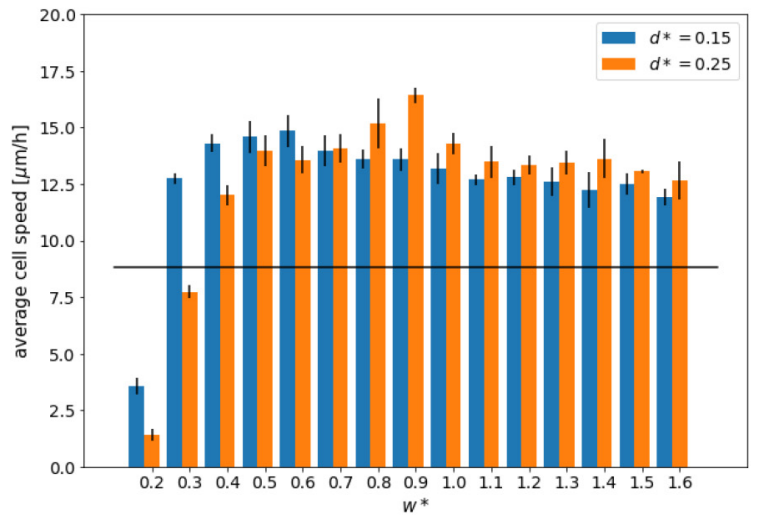

(d) Evolution of the average cell speed as a function of $w^{*}$ for $d^{*}=0.15$ (blue bars) and 0.25 (orange bars

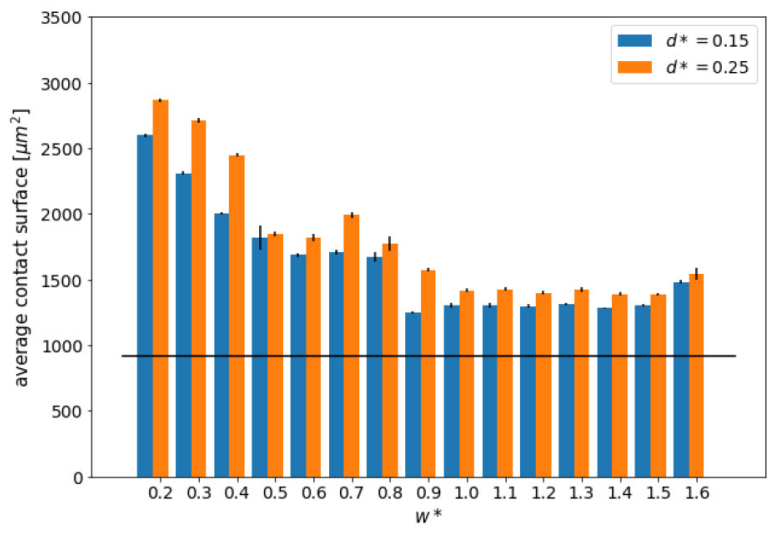

(e) Evolution of the average contact surface as a function of $w^{*}$ for $d^{*}=0.15$ (blue bars) and 0.25 (orange bars)

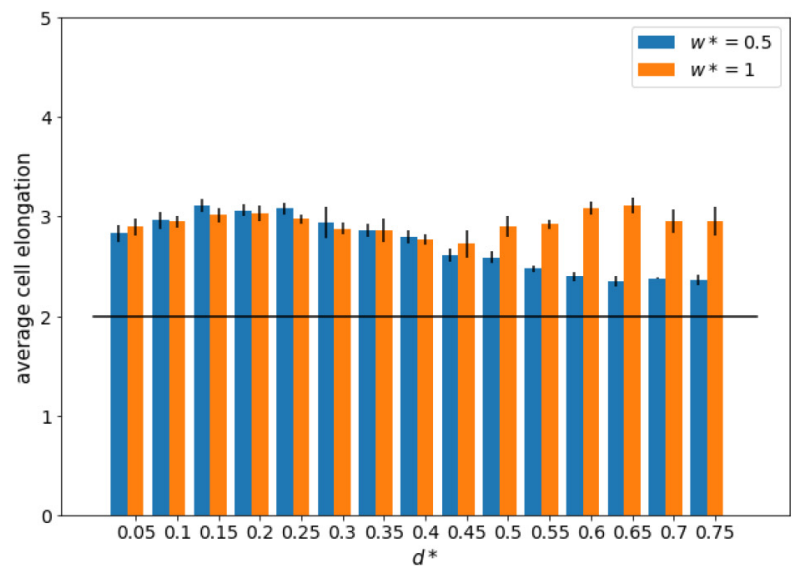

(c) Evolution of the average cell elongation $\left(\frac{a}{c}\right)$ as a function of $d^{*}$ for $w^{*}=0.5$ (blue bars) and 1 (orange bars)

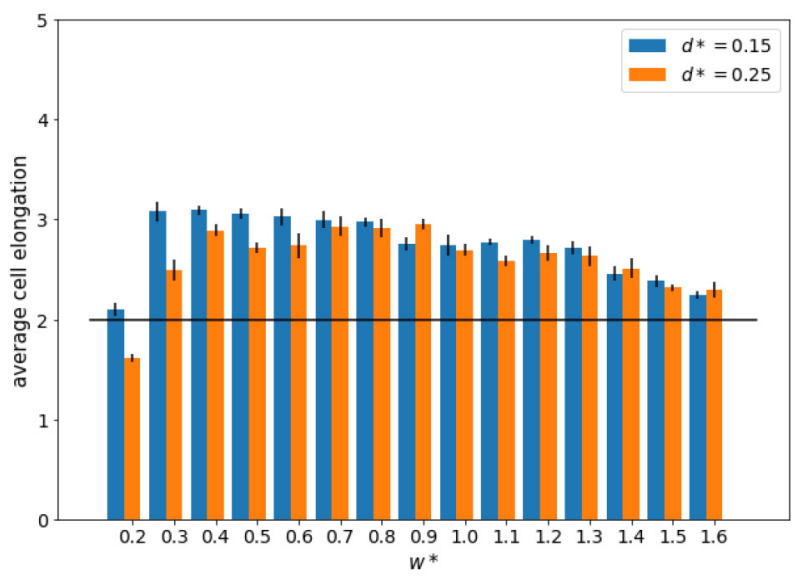

(f) Evolution of the average cell elongation $\left(\frac{a}{c}\right)$ as a function of $w^{*}$ for $d^{*}=0.15$ (blue bars) and 0.25 (orange bars)

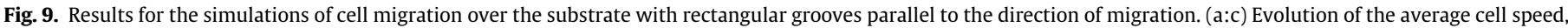

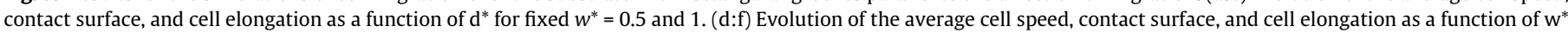
for fixed $d^{*}=0.15$ and 0.25 . The black lines represent the average value of the specific parameter for the simulation on the smooth surface. 
Afterwards, a low decrease occurs down to $2.3( \pm 0.08)$ at $w^{*}=1.6$. The value of the cell elongation for $w^{*}=0.2$ is significant lower compared to the smooth surface. No significant correlation was found between the evolution of the cell speed and the cell elongation $(\mathrm{p}>0.05)$.

\subsubsection{Rectangular perpendicular grooves}

In the case of the surface with rectangular grooves oriented perpendicularly to the direction of motion, the resting position gives the same results as for the rectangular parallel grooves (Fig. 7), with the cell here aligned in the direction of the grooves and perpendicularly to the direction of migration.

When the cell starts moving via the external potential, its trajectories show some deviation of the COM in the Y direction compared to the initial position, with a lower distance covered compared to the rectangular parallel grooves (Fig. 10a). In terms of contact surface (Fig. 10b), the surface increases from $940 \mu \mathrm{m}^{2}$, and then displays a sinusoidal variation around $1600 \mu \mathrm{m}^{2}$ that can be explained by the cell crossing the grooves to be able to migrate. Concerning the cell shape (Fig. 10c), the results show that the cell adapts its morphology to the substrate, leading to a slight increase of $\frac{a}{c}$ up to an average value of 2.6. Such a behaviour is the result of an unnatural motion of the cell due to the combination of the surface topography (i.e. the rectangular perpendicular grooves) and the direction of the external potential. Both the contact surface and the cell elongation show significant differences between each simulation, due to the small variations added at the crossing of each groove.

Similarly to the case of the rectangular parallel grooves, two separate studies were performed to analyse the influence of $w^{*}$ and $d^{*}$ on the cell migration. The first one simulates the cell migration as a function of $d^{*}$ for two fixed values of $w^{*}$ (Fig. 11a:c). The second one simulates the cell migration as a function of $w^{*}$ for two fixed values of $d^{*}$ (Fig. $11 \mathrm{~d}: \mathrm{f}$ ).

Fig. 11a shows the evolution of the cell speed as a function of $d^{*}$ for $w^{*}=0.5$ and 1 . A general decrease of the cell speed is observed as $d^{*}$ increases from 0.05 to 0.75 , from $8.2 \mu \mathrm{m} / \mathrm{h}( \pm 0.7)$ to $2.3 \mu \mathrm{m} / \mathrm{h}$ $( \pm 0.9)$ for $w^{*}=0.5$, and from $8.2 \mu \mathrm{m} / \mathrm{h}( \pm 0.4)$ to $1.9 \mu \mathrm{m} / \mathrm{h}( \pm 0.3)$ for $w^{*}=1$. Beyond $d^{*}=0.15$, the cell stops migrating and is stuck to the surface for $w^{*}=0.5$. The same phenomenon is observed for $w^{*}=1$ beyond $d^{*}=0.4$. The cell speed is significantly lower than one found for the case of the smooth surface and it is generally higher for $w^{*}=1$ compared to $w^{*}=0.5$. This confirms the difficulty of the cell to move in the direction of the external potential due to the presence of the perpendicular grooves. From an energetic point of view, the cell needs more energy to move, resulting in a lower cell speed.
In terms of shape, at low $d^{*}$, the cell succeeds to migrate by constantly changing its shape when passing the grooves. However, beyond $d^{*}=0.15$ for $w^{*}=0.5$ and $d^{*}=0.35$ for $w^{*}=1$, the cell permanently acquires the shape of the rectangular groove, thus perpendicular to the direction of motion, and stops migrating. This is reflected by an increase of the contact surface (Fig. 11b), from $1400 \mu \mathrm{m}^{2}( \pm 99)$ at $d^{*}=0.05$ to $3034 \mu \mathrm{m}^{2}( \pm 24)$ at $d^{*}=0.45$ for $w^{*}=0.5$. For $w^{*}=1$, an increase of the contact surface is also observed, from $1465 \mu \mathrm{m}^{2}( \pm 11)$ at $d^{*}=0.05$ to $2214 \mu \mathrm{m}^{2}( \pm 29)$ at $d^{*}=0.35$. The values of the contact surface are significant higher compared to the smooth surface. In terms of cell elongations (Fig. 11c), an increase is registered for $w^{*}=0.5$ as $d^{*}$ increases from 0.15 to 0.35 , from $2.71( \pm 0.23)$ to $5.6( \pm 0.2)$. Simultaneously, a small decrease of $\frac{a}{c}$ is observed down to $4.92( \pm 0.24)$ at $d^{*}=0.75$ (Fig. 11c). For $w^{*}=1$, an increase is registered from $2.87( \pm 0.14)$ at $d^{*}=0.3$ to $4.84( \pm 0.25)$ at $d^{*}=0.45$, followed by a decrease down to 0.75 with $2.68( \pm 0.56)$. As for $w^{*}=0.5$, the increase of the cell elongation at $d^{*}=0.3$ coincides with the interruption of the cell migration. In addition, a fragmentation of the cell in two or more parts is observed beyond $d^{*}=0.5$ for $w^{*}=0.5$, and beyond $d^{*}=0.65$ for $w^{*}=0.5$.

The evolutions of the cell speed as a function of $w^{*}$ for $d^{*}=0.15$ and $d^{*}=1$ are reported in Fig. $11 \mathrm{~d}$. A general increase in cell speed is measured as $w^{*}$ increases from 0.2 to 1.6 , regardless the value of $d^{*}$. For $d^{*}=0.15$, the cell speed is considered null for $w^{*}$ lower than 0.4 , then it increases from $0.75 \mu \mathrm{m} / \mathrm{h}( \pm 0.1)$ to $7.5 \mu \mathrm{m} / \mathrm{h}( \pm 0.4)$ at $w^{*}=1.6$. In the case $d^{*}=0.25$, the cell speed is considered null until $w^{*}=0.6$, then it increases from $0.44 \mu \mathrm{m} / \mathrm{h}( \pm 0.06)$ to $5.89 \mu \mathrm{m} / \mathrm{h}$ $( \pm 0.15)$ at $w^{*}=1.6$. The cell speed is significantly lower than the one found in the case of the smooth surface. In terms of shape, low $w^{*}(<1)$ correspond to the cell orienting along the rectangular grooves and acquiring their shape. For higher $w^{*}$, the cell becomes ellipsoidal. This can also be seen in the evolution of the cell elongation (Fig. 11f), where different evolutions are observed depending on $d^{*}$. For $d^{*}=0.15$, an increase of the cell elongation is registered from $2.41( \pm 0.11)$ at $w^{*}=0.2$ to $3.54( \pm 0.11)$ at $w^{*}=0.4$, corresponding to the phase where the cell is stuck on the surface and acquires the shape of the rectangular grooves with the increase of $w^{*}$. Beyond $w^{*}=0.4$, the cell starts to migrate, and a decrease of the cell elongation is observed down to $2.69( \pm 0.05)$ at 1 where the value stabilises. Similarly to $d^{*}=0.15$, the evolution of the cell elongation for $d^{*}=0.25$ presents an increase from $1.76( \pm 0.04)$ at $w^{*}=0.2$ until $4.1( \pm 0.07)$ at $w^{*}=0.6$, during which the cell acquires the shape of the rectangular grooves and followed, beyond $w^{*}=0.6$, by the start of the migration and a decrease of the cell elongation until 2.76 $( \pm 0.05)$ at 1.2 . In terms of contact surface (Fig. 11e), we observe a

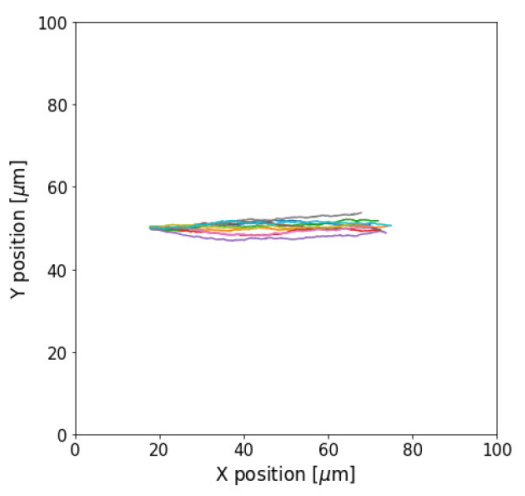

(a) Cell trajectories in the $(X-Y)$ plane

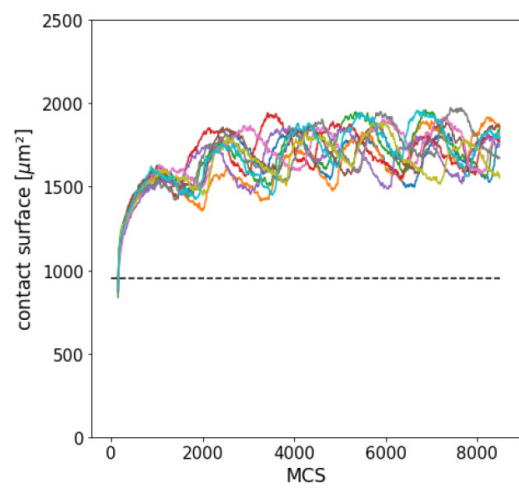

(b) Evolution of the contact surface.

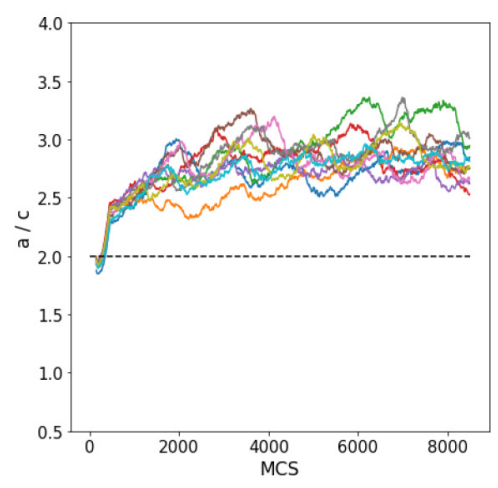

(c) Evolution of $\frac{a}{c}$.

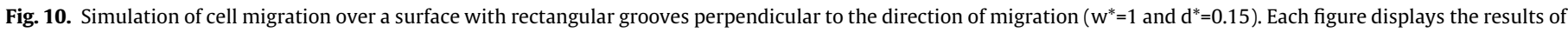
ten simulations. The black horizontal dot lines represent the average value of the specific parameter for the simulations on the smooth surface. 


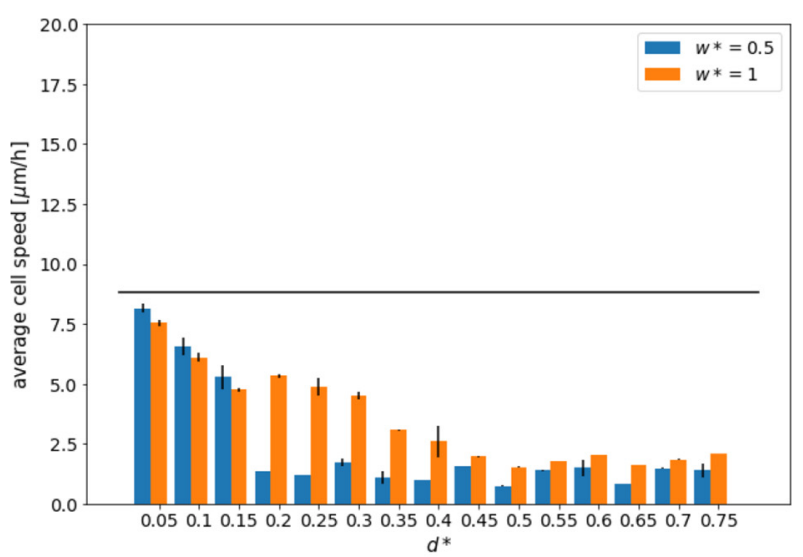

(a) Evolution of the average cell speed as a function of $d^{*}$ for $w^{*}=0.5$ (blue bars) and 1 (orange bars)

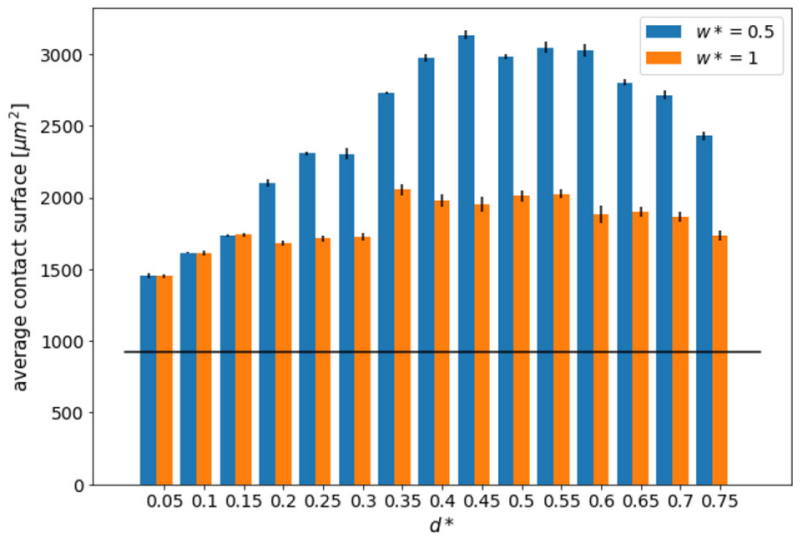

(b) Evolution of the average contact surface as a function of $d^{*}$ for $w^{*}=0.5$ (blue bars) and 1 (orange bars)

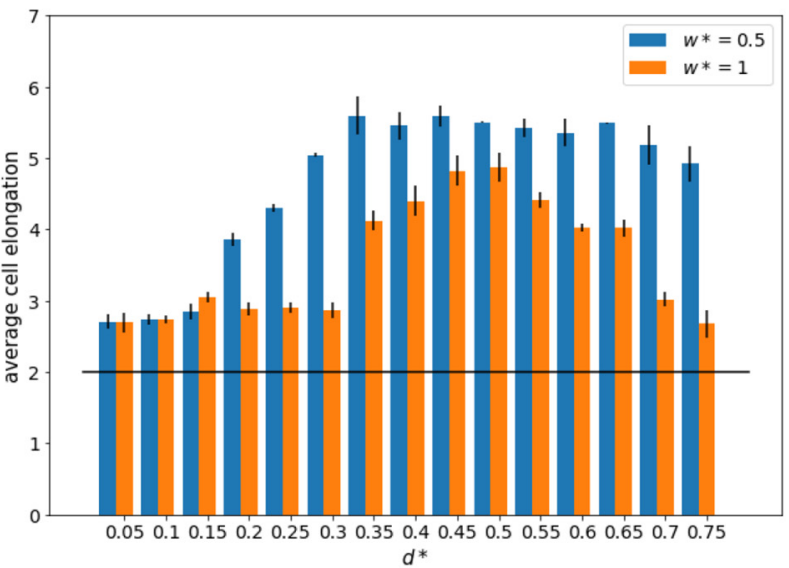

(c) Evolution of the average cell elongation $\left(\frac{a}{c}\right)$ as a function of $d^{*}$ for $w^{*}=0.5$ (blue bars) and 1 (orange bars)

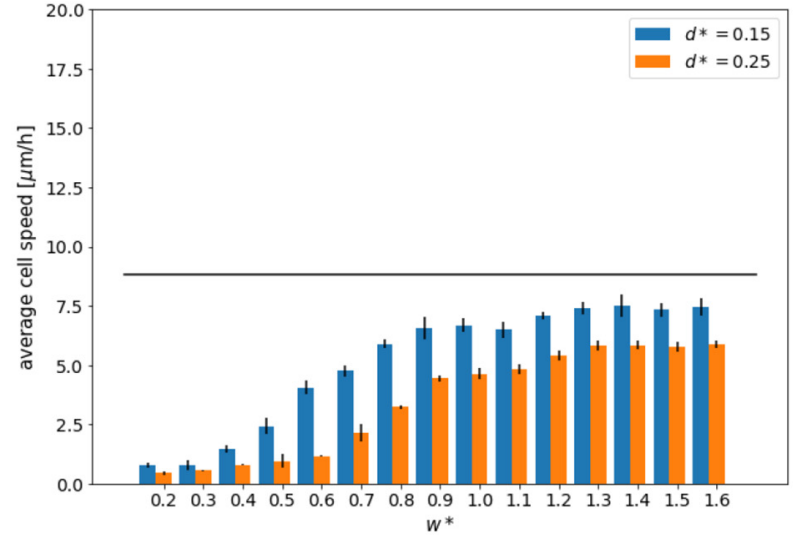

(d) Evolution of the average cell speed as a function of $w^{*}$ for $d^{*}=0.15$ (blue bars) and 0.25 (orange bars)

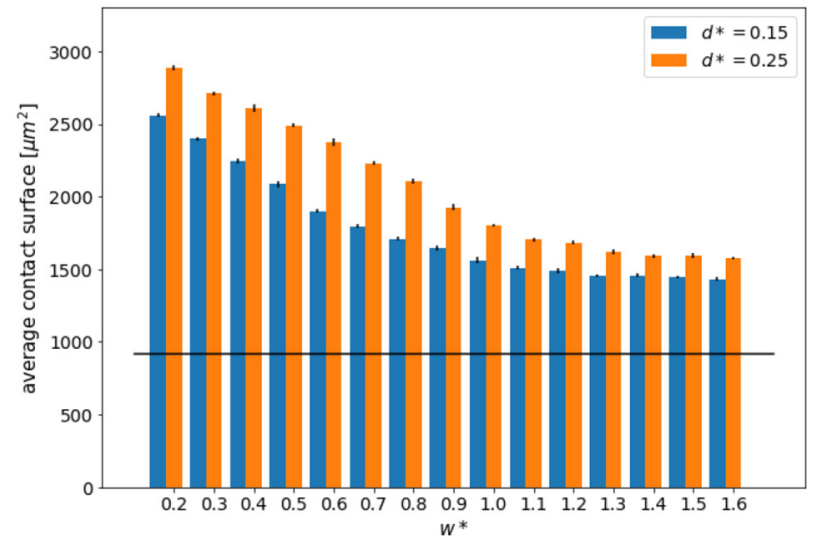

(e) Evolution of the average contact surface as a function of $w^{*}$ for $d^{*}=0.15$ (blue bars) and 0.25 (orange bars)

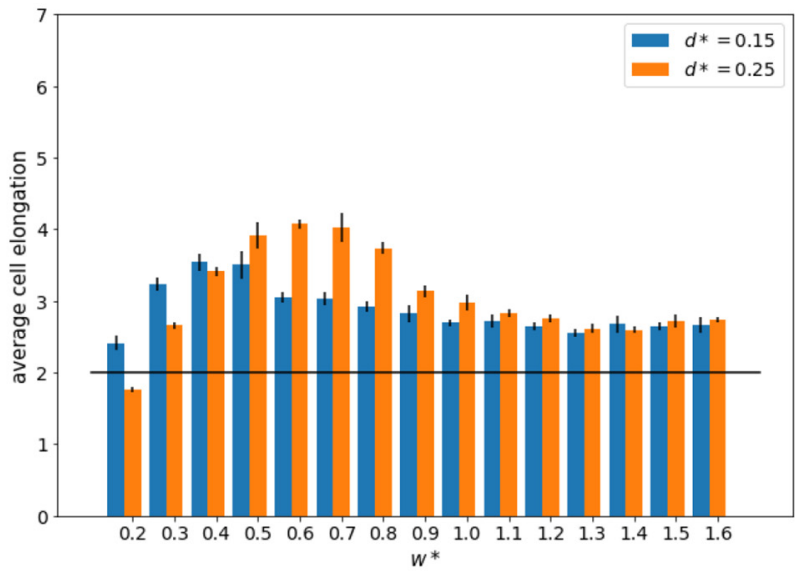

(f) Evolution of the average cell elongation $\left(\frac{a}{c}\right)$ as a function of $w^{*}$ for $d^{*}=0.15$ (blue bars) and 0.25 (orange bars)

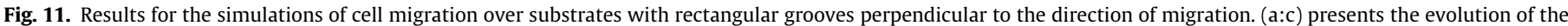

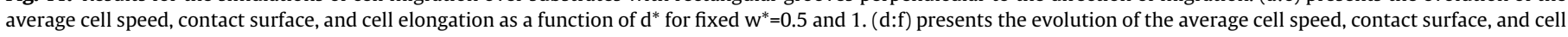

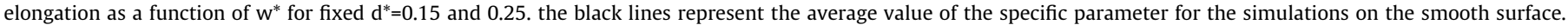


decrease as $w^{*}$ increases from 0.2 to 1.6 regardless $d^{*}$, from $2886 \mu \mathrm{m}^{2}( \pm 18)$ to $1575 \mu \mathrm{m}^{2}( \pm 7)$ for $d^{*}=0.15$, and from $2558 \mu \mathrm{m}^{2}( \pm 11)$ to $1433 \mu \mathrm{m}^{2}( \pm 15)$ for $d^{*}=0.25$. The values of the contact surface are significant higher compared to the smooth surface and they are correlated to $r_{c}(\mathrm{r}=1, \mathrm{p} \ll 0.05)$ as well. No relationship is found between the cell elongation and the contact surface.

\subsubsection{Influence of the grooves size and orientation}

Our numerical results highlight the effects of the rectangular groove and more specifically of their dimensions $\left(w^{*}\right.$ and $\left.d^{*}\right)$ on cell migration.

If we look at the results in terms of cell speed (Fig. 9a and 11a), we notice an initial increase of the speed with $d^{*}$ regardless $w^{*}$ as well as an increase of the cell elongation (see Movie S3). Nonetheless, this initial increase is followed by a decrease that will vary depending on $w^{*}$ and, beyond a specific value of $d^{*}$, the rectangular groove can evidently inhibit the cell migration. For rectangular grooves with width values equal to the diameter $D$ of the cell, the results show that the cell speed is higher compared to the case of the smooth surface, independently of the groove depth. This is followed by a high cell elongation (i.e. higher than 2.5) regardless the groove depth. On the contrary, for rectangular grooves with a width values equal to the radius of the cell, the cell speed is higher than the one on the smooth surface for $d^{*}$ between 0.05 and 0.55 . For values of $d^{*}$ higher than 0.55 , a lower cell speed is found since the cell is inhibited by the rectangular grooves during its motion, and this whole evolution is followed by a decrease in cell elongation. Only a few studies analyse the influence of $d^{*}$ at the microscale. Among them, the work of Dalton et al (Dalton, 2001) confirms our results by highlighting the increase in collective cell migration distance over rectangular microgrooves with various widths compared to a smooth surface, with a decrease of the migration distance as the depth of the microgrooves increases from 1 to $5 \mu \mathrm{m}$. Regarding the influence of $w^{*}$, the results show an optimal value depending on $d^{*}$ (but always inferior to the radius of the cell), for which the influence of the rectangular grooves on the cell speed is maximal. This optimal value is also observed for the cell elongation. This confirms the interdependence of $w^{*}$ and $d^{*}$ influencing the global behaviour of the cell. Nonetheless, beyond this specific value of $w^{*}$, the decrease of the cell elongation, as $w^{*}$ increases, is due to a lower influence of the surface topography. Thus, the higher the width $w^{*}$, the lower the influence on the cell. If we look at the literature, several studies validate our findings. Dalton et al. (2001) showed that, in the case of the rectangular grooves, for each depth $d^{*}$ analysed, a maximum value of cell speed is found for the width varying between 1 and $10 \mu \mathrm{m}$. Similarly, Uttayarat et al. (2008) observed an increase of the cell speed and the alignment of the cell on rectangular grooves substrate compared to the smooth substrate, with a maximum value of the migration speed for a width $w^{*}=6 \mu \mathrm{m}$ followed by a decrease at $w^{*}=10 \mu \mathrm{m}$. These data confirm the guiding effect of the rectangular grooves on cell migration and optimal values of $w^{*}$ and $d^{*}$ exist to obtain the most efficient behaviour of the cell in terms of cell speed. Besides, our model provides a new point of view since we assume that the minimisation of the energy triggers the alignment of the cell with the rectangular grooves, resulting in a volume distribution which facilitates the motion, although cell internal dynamics are not modelled. It can be pointed out that at low $w^{*}$ (lower than 0.3 ) for $d^{*} \geq 0.15$, we observe a decrease of the cell speed and of the cell elongation compared to the case of the smooth surface, leading to an inhibition of the cell motion. If we compare our results to the data from the literature, most of the grooved surfaces considered in other works have low width $w^{*}$. However, most of these same surfaces were defined with a groove depth lower or equal to $1 \mu \mathrm{m}$ and our results have shown an improvement in cell migration for such value of $d^{*}$. We can assume that this behaviour is exclusive to our model for which the contact between the cell and the substrate is maximised. A further reason of such outcome can be the condition $d^{*}>w^{*}$ that seems to be unfavourable to the cell motion. Furthermore, although no significant relationships have been proven between the cell speed and the cell elongation, it seems that an increase in cell speed is linked to an increase in cell elongation. Nonetheless, we cannot show which parameter $\left(d^{*}\right.$ or $\left.w^{*}\right)$ is predominant at this stage. Regarding the contact surface, it globally follows the evolution of the roughness ratio $r_{c}$ (see Table 4 in Appendix A.1). All the configurations improving the cell migration (i.e. the cell speed) present a higher contact surface with the substrate, compared to the case of the smooth one. Thus, we can conclude that the contact surface plays a significant role in the cell migration. However, no correlations are found between the cell speed and the contact surface.

Regarding the influence of the orientation of the grooves, our findings change completely compared to the previous statement. If we look at the results of the rectangular perpendicular grooves, we observed an inhibitor factor of the surface with lower values of cell speed compared to the smooth surface, regardless $w^{*}$ and $d^{*}$. We notice a decrease in cell speed with an increase in $d^{*}$, confirmed by Dalton et al. (2001), and a decrease in $w^{*}$, as observed by Cheng et al. (2019). For low $d^{*}$ (lower than 0.3), the cell is able to migrate on the surface by constantly changing its shape. However, for higher $d^{*}$, the cell is trapped on the surface, and it acquires the shape and the orientation of the grooves. On the contrary, for low $w^{*}$ (lower than 0.5 ), the cell globally remains stuck on the surface and cannot migrate. However, for higher $w^{*}$ (around 1), the cell is able to migrate (see Movie S4). Thus, contrarily to the case of rectangular parallel grooves, high $d^{*}$ and low $w^{*}$ act as inhibitors to the cell motion. The results are in agreement with various studies of the literature which analyse cell migration in the same configuration. While Dalton et al. (2001) observed a drop in cell speed with the increase $d^{*}$, Cheng et al. (2019) showed the same trend as of our results with an increase of the cell speed as $w^{*}$ increases from $20 \mu \mathrm{m}$ to 150 from. It has to be said that the study of Cheng et al. (2019) was performed on sinusoidal grooves, but we assume that their results can be extrapolated. Our simulations on rectangular perpendicular grooves have also shown the appearance of cell fragmentation for high $d^{*}$ (higher than 0.5 ), that obviously does not happen in reality. Such a behaviour can be due to the numerical condition constraining the cell to fully adhere to the substrate. Nonetheless, such mechanism occurs only when the cell is not able to migrate. Overall, our results show that the orientation of the grooves is yet another factor influencing the behaviour of the cell.

\subsection{Cell migration on sinusoidal parallel grooves}

Hu et al. (2014) showed that cells migrating on wavy surface displayed both improved alignment and adhesion strength as well as a lower death rate. Andersson et al. (2003) pointed out higher alignment and cell elongation on grooves with continuous edges compared to the discontinuous ones. Although the reasons behind such improvements are still unclear, they both assume that surface topography plays a critical role. According to these data, in the third set of simulations, we analyse the influence of the sinusoidal parallel grooves on cell migration (Fig. 12a). The grooves are defined by a normalised amplitude $A^{*}$ and a normalised wavelength $\lambda^{*}$ along the $\mathrm{Y}$ axis. The adhesion parameter $J_{c s}$ is fixed and equal to $1.10^{-15} \mathrm{~kg} / \mathrm{s}^{2}$.

The analysis of the shape of the cell on the sinusoidal grooved surface without any external potential (Fig. 12 and Movie S5) 


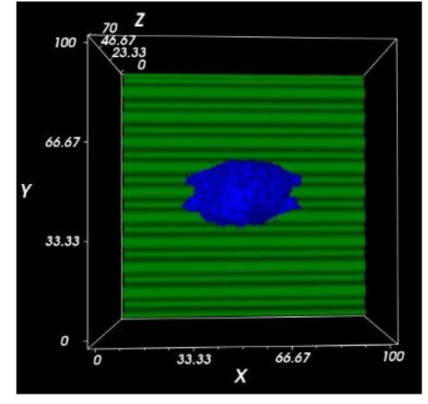

(a) $3 D$ view of the cell on sinusoidal parallel grooves

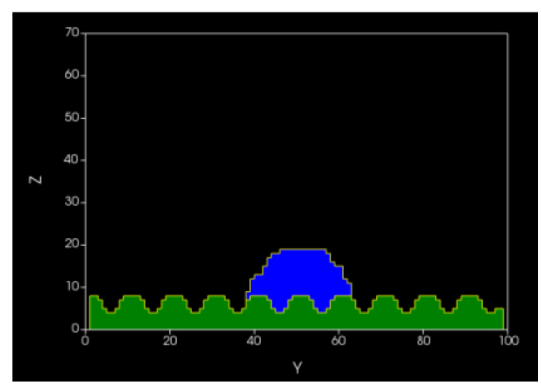

(b) (X-Z) view of the cell on sinusoidal parallel grooves

Fig. 12. Shape of the cell at the resting position on the surface with sinusoidal parallel grooves. Here, the sinusoidal grooves are defined by $\lambda^{*}=0.5$ and $A^{*}=0.25$.

shows that the cell aligns itself along the grooves, as for the case of the surface with rectangular parallel grooves (Fig. 7).

Fig. 13 presents the results of the cell migration on the surface with sinusoidal parallel grooves in terms of trajectories (Fig. 13a), contact surface (Fig. 13b) and cell elongation $\frac{a}{c}$ (Fig. 13c). Similarly to the case of the rectangular parallel grooves, the cell follows the direction of the external potential (i.e. the X direction). In terms of contact surface, the evolution is similar to the rectangular parallel grooves, with a maximal value around $1720 \mu \mathrm{m}^{2}$. As for the shape, the cell mostly stretches in the X direction aligning itself with the sinusoidal grooves. This is confirmed by an increase of $\frac{a}{c}$ up to an average value of 2.6 , that seems lower than the elongation on the rectangular parallel grooves for the same dimension values.

As for the previous configurations, two separate studies were performed to analyse the influence of $\lambda^{*}$ and $A^{*}$ on cell migration. The first one simulates the cell migration as a function of $A^{*}$ for two fixed values of $\lambda^{*}$ (Fig. 14a:c). Contrary to the rectangular grooved substrate, the study of $A^{*}$ starts here at $A^{*}=0.1$ (i.e. $A=2 \mu \mathrm{m}$ ) to be able to obtain a sinusoidal structure. The second one simulates the cell migration as a function of $\lambda^{*}$ for two fixed values of $A^{*}$ (Fig. 14d:f).

The evolution of the cell speed as a function of $\lambda^{*}$ for $A^{*}=0.15$ and $A^{*}=1$ is reported in Fig. 14a. For $\lambda^{*}=0.5$, a general increase is observed as $A^{*}$ increases from 0.1 to 0.25 , from $11.6 \mu \mathrm{m} / \mathrm{h}( \pm 0.4)$ to $15 \mu \mathrm{m} / \mathrm{h}( \pm 0.5)$. After attaining this maximum value, a decrease is observed down to $8.1 \mu \mathrm{m} / \mathrm{h}( \pm 0.3)$ at $d^{*}=0.8$. The cell speed for $\lambda^{*}=0.5$ is higher than in the case of the smooth surface for values of $A^{*}$ from 0.1 to 0.7 . For $\lambda^{*}=1$, the increase of $A^{*}$ from 0.1 to 0.4 cor- responds to a decrease of the cell speed from $10.6 \mu \mathrm{m} / \mathrm{h}( \pm 0.4)$ to $7.9 \mu \mathrm{m} / \mathrm{h}( \pm 0.14)$. Afterwards, no significant differences are found for $A^{*}$ increasing from 0.45 to 0.8 . As for $\lambda^{*}=0.5$, the cell speed at $\lambda^{*}=1$ is higher than in the case of the smooth surface for values of $A^{*}$ from 0.1 to 0.35 . In terms of cell shape, we observe a clear elongation of the cell in the direction of the pattern, i.e. the $\mathrm{X}$ direction (see Movie S5), with an increase of the external envelope of the cell. In terms of the contact surface (Fig. 14b), an increase is registered for both $\lambda^{*}$ as $A^{*}$ increases, from $1618 \mu \mathrm{m}^{2}( \pm 15)$ at $A^{*}=0.1$ to $2947 \mu \mathrm{m}^{2}( \pm 29)$ at $A^{*}=0.3$ for $\lambda^{*}=0.5$, and from $1533 \mu \mathrm{m}^{2}( \pm 5)$ at $A^{*}=0.1$ to $2188 \mu \mathrm{m}^{2}( \pm 87)$ at $A^{*}=0.55$ for $\lambda^{*}=1$. No significant differences are found both $\lambda^{*}$. The values of contact surface for both $\lambda^{*}$ are significant higher compared to the case of the smooth surface. In terms of cell elongation (Fig. 14c), a small increase is observed for $\lambda^{*}=0.5$ with $A^{*}$ increasing from 0.1 to 0.25 , from $2.75( \pm 0.03)$ to $2.92( \pm 0.05)$, followed by a decrease until $2.14( \pm 0.05)$ at $A^{*}=0.8$. For $\lambda^{*}=1$, we observe a general decrease for $A^{*}$ increasing from 0.1 to 0.8 , from $2.75( \pm 0.03)$ to $2.14( \pm 0.05)$ for $\lambda^{*}=0.5$. The cell elongation is higher than in the case of the smooth surface for values of $A^{*}$ from 0.1 to 0.65 . Afterwards, no significant differences are found. No significant relationship is found between the evolution of the cell speed and the cell elongation $(p>0.05)$.

Fig. 14d reports the values of cell speed for different values of the normalised depth $\lambda^{*}$ at fixed amplitude $A^{*}$. For $A^{*}=0.15$, an increase of the cell speed is measured from $9.2 \mu \mathrm{m} / \mathrm{h}( \pm 0.3)$ at $\lambda^{*}=0.2$ up to $12.4 \mu \mathrm{m} / \mathrm{h}( \pm 1)$ at $\lambda^{*}=0.5$. Then, a decrease of the cell speed is registered at $11.3 \mu \mathrm{m} / \mathrm{h}( \pm 0.13)$ for $\lambda^{*}=0.75$. Except for $\lambda^{*}=0.2$, the cell speed is significantly higher than the cell speed

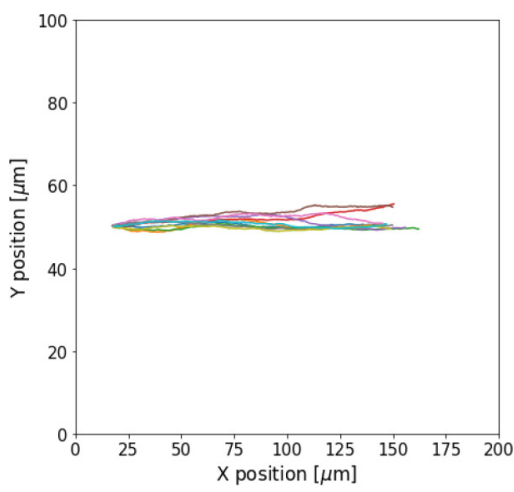

(a) Cell trajectories in the $(X-Y)$ plane

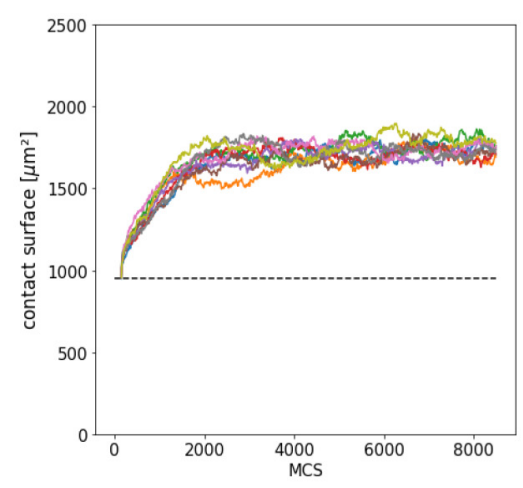

(b) Evolution of the contact surface.

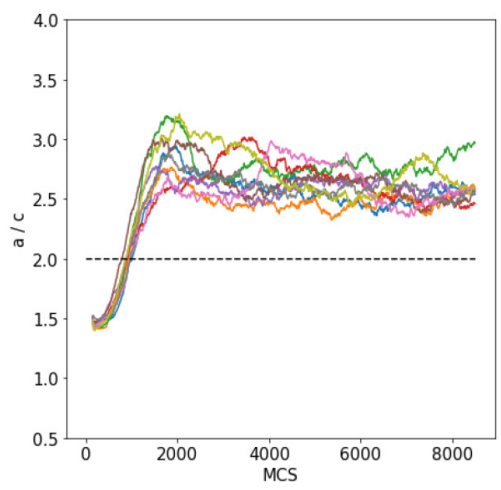

(c) Evolution of $\frac{a}{c}$

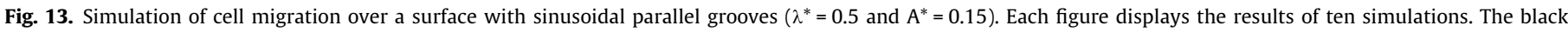
horizontal dot lines represent the average value of the specific parameter for the simulations on the smooth surface. 


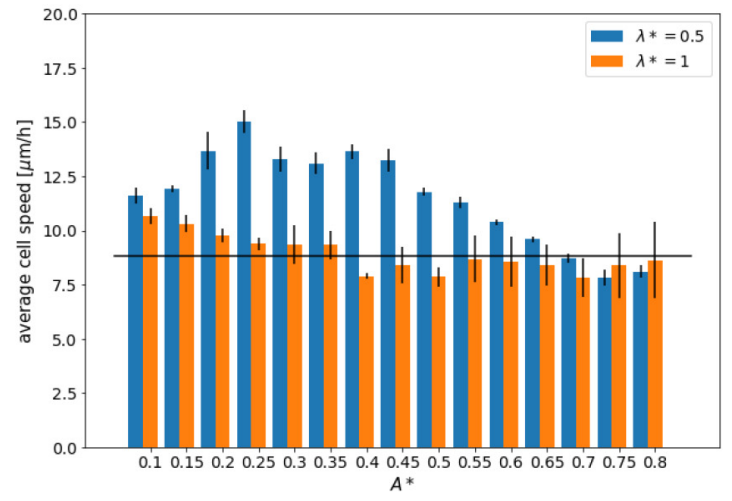

(a) Evolution of the average cell speed as a function of $A^{*}$ for $\lambda^{*}=0.5$ (blue bars) and 1 (orange bars)

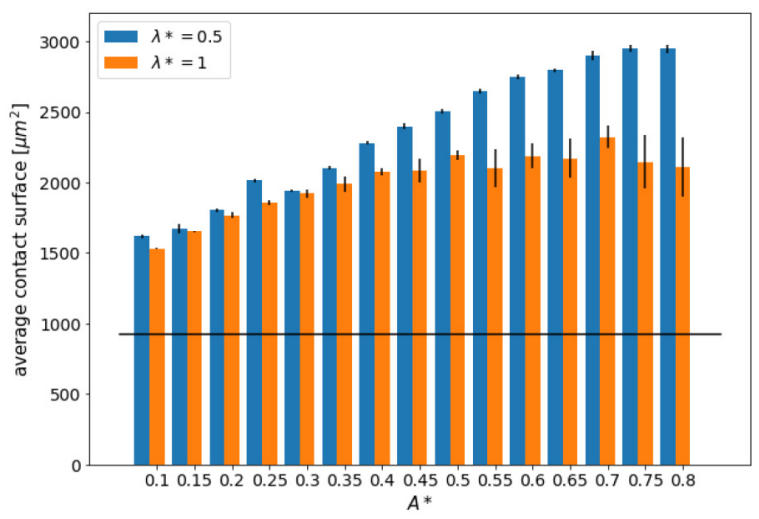

(b) Evolution of the average contact surface as a function of $A^{*}$ for $\lambda^{*}=0.5$ (blue bars) and 1 (orange bars)

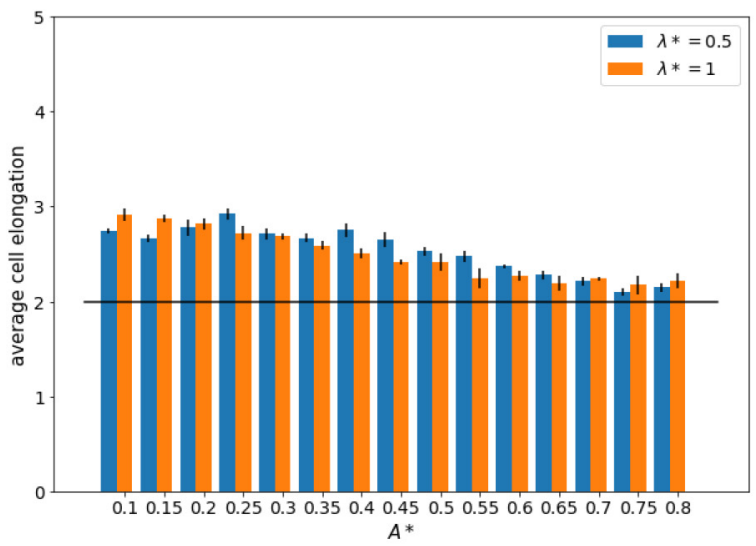

(c) Evolution of the average cell elongation $\left(\frac{a}{c}\right)$ as a function of $A^{*}$ for $\lambda^{*}=0.5$ (blue bars) and 1 (orange bars)

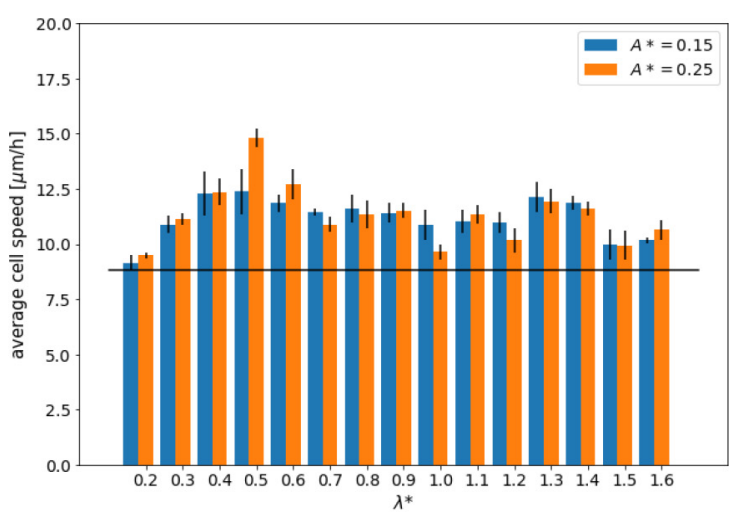

(d) Evolution of the average cell speed as a function of $\lambda^{*}$ for $A^{*}=0.15$ (blue bars) and 0.25 (orange bars)

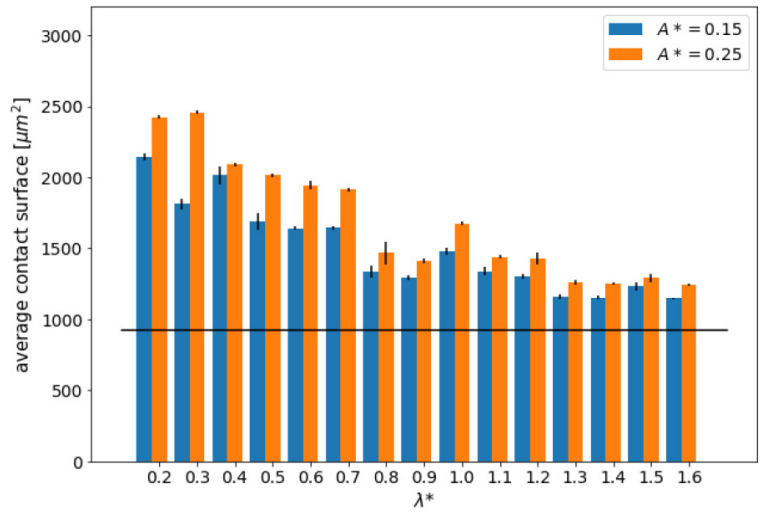

(e) Evolution of the average contact as a function of $\lambda *$ for $A^{*}=0.15$ (blue bars) and 0.25 (orange bars)

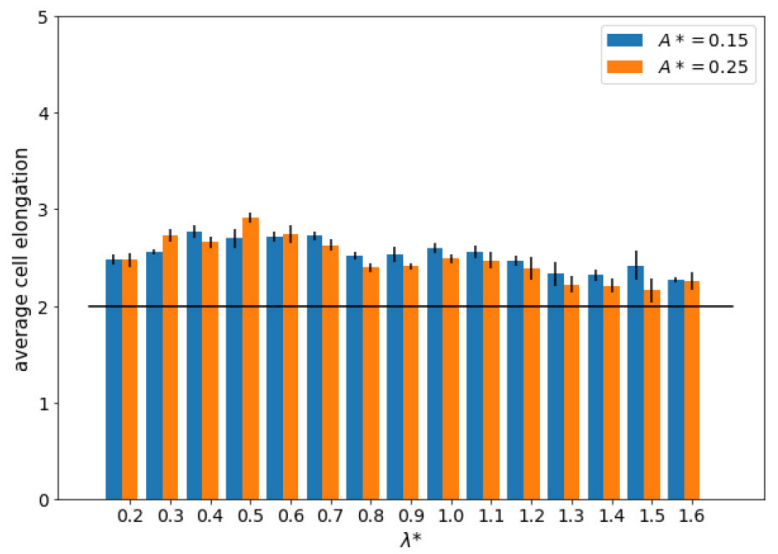

(f) Evolution of the average cell elongation $\left(\frac{a}{c}\right)$ as a function of $\lambda^{*}$ for $A^{*}=0.15$ (blue bars) and 0.25 (orange bars)

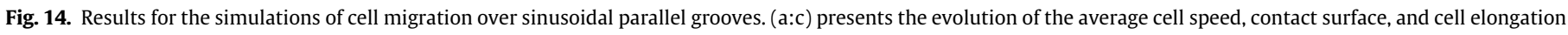

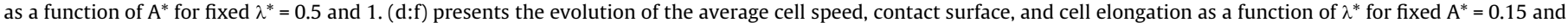
0.25 . The black lines represent the average value of the specific parameter for the simulations on the smooth surface.

on smooth surface. For $A^{*}=0.25$, an increase of the cell speed is observed from $9.5 \mu \mathrm{m} / \mathrm{h}( \pm 0.1)$ at $\lambda^{*}=0.2$ to $14.8 \mu \mathrm{m} / \mathrm{h}( \pm 0.4)$ at $\lambda^{*}=0.5$, followed then by a decrease down to $11.8 \mu \mathrm{m} / \mathrm{h}( \pm 0.4)$ at $\lambda^{*}=1.6$. The cell speed is significantly higher than the cell speed in the case of the smooth surface, regardless the value of $\lambda^{*}$. In terms of the contact surface for $A^{*}=0.15$ and $A^{*}=0.25$ (Fig. 14e), both of them show a general decrease from $2142 \mu \mathrm{m}^{2}( \pm 23)$ at $\lambda^{*}=0.2$ to $1149 \mu \mathrm{m}^{2}( \pm 4)$ at $\lambda^{*}=1.6$ for $A^{*}=0.15$, and from $2424 \mu \mathrm{m}^{2}( \pm 16)$ at $\lambda^{*}=0.2$ to $1245 \mu \mathrm{m}^{2}( \pm 9)$ at $\lambda^{*}=1.6$ for $A^{*}=0.25$. The contact surface is significantly higher compared to the smooth 
surface, regardless the value of $\lambda^{*}$ and $A^{*}$. This outcome is consistent with the fact that the higher $\lambda^{*}$, the more the surface becomes flat from the point of view of the cell, which results in a lower impact on the cell motion. This is corroborated by the evolution of the cell elongation (see Fig. 14f). For $A^{*}=0.15$, after a small increase from $2.48( \pm 0.05)$ at $\lambda^{*}=0.2$ to $2.77( \pm 0.06)$ at $\lambda^{*}=0.4$, a low decrease is observed down to $2.27( \pm 0.03)$ at $\lambda^{*}=1.6$. For $A^{*}=0.25$, the same trend is found with a maximum value of $a$ of $2.91( \pm 0.05)$ at $\lambda^{*}=0.5$ and a minimum value of $\frac{a}{c}$ of $2.15( \pm 0.12)$ at $\lambda^{*}=1.5$. The cell elongation is significantly higher than the cell elongation on the smooth surface, regardless the value of $\lambda^{*}$ and $A^{*}$. No significant correlation is found between the evolution of the cell speed and the cell elongation $(\mathrm{p}>0.05)$.

To summarise the results, the sinusoidal parallel grooves affect the cell migratory behaviour in the same way as the rectangular parallel grooves (see Section 3.2.1). The guiding effect of the sinusoidal grooves depends on $A^{*}$ and $\lambda^{*}$, with an interdependency as well. The increase of $A^{*}$ shows an improvement of the cell migration (i.e. higher cell speed) for low $A^{*}$ (lower than 0.25), with a slight increase in cell elongation. However, higher values of $A^{*}$ let disappearing the positive influence of the sinusoidal parallel grooves on the cell migration with a stagnation of the cell speed. At this stage, no explanation could be found for such a behaviour. However, the simultaneous stagnations of the contact surface and of the cell elongation let us assume that the sinusoidal grooves act like a channel at the cell level, with their dimensions remaining the same beyond a specific depth $A^{*}$ (here around 0.5 ). The same phenomenon was observed for the rectangular parallel grooves beyond $d^{*}=0.6$. Regarding the influence of $\lambda^{*}$, our results follow the trend showed in the study of Cheng et al. (2019), where they found that at a fixed amplitude, an increase of $\lambda$ leads to a decrease in cell speed, with the maximum speed obtained for $\lambda=20 \mu \mathrm{m}$. These findings are consistent with the fact that higher values of $\lambda^{*}$ result in a flatter surface from the point of view of the cell, leading to a less significant influence of the topography on the motion of the cell. If we compare these results to those obtained for the surface with the rectangular parallel grooves, the cell speed on the rectangular ones is globally higher than the one on the sinusoidal parallel grooves for the same dimensions of the grooves $\left(w^{*}=\lambda^{*}\right.$ and $\left.d^{*}=A^{*}\right)$, especially for $w^{*} \mid \lambda^{*}=1$. The same result is found in terms of cell elongation which is also globally higher on the rectangular grooves. This outcome is consistent with the data from Cheng et al. (2019), where they compared cell migration on rectangular and sinusoidal grooves, and proved a better migration on the rectangular ones. By comparing the values of $r_{c}$ (Table 5 from Appendix A.1), we can see that the roughness ratio $r_{c}$ is higher on the rectangular parallel grooves than on the sinusoidal parallel grooves. The comparison of the contact surface shows no significant differences for $w^{*} / \lambda^{*}=0.5$. However, we notice a lower contact surface for the rectangular parallel grooves for $w^{*} / \lambda^{*}=1$ compared to the sinusoidal parallel grooves. This could suggest that the guiding effect of the sinusoidal grooves is lower than the rectangular parallel grooves. Such outcome is also confirmed by the evolution of the cell elongation, which is higher on the rectangular parallel grooves than on the sinusoidal parallel grooves. This may be explained by the discontinuity of the rectangular grooves having a higher guiding effect on the cell. We also notice that, compared to the rectangular grooves, the sinusoidal grooves offer a slightly lower available surface of contact to the cell. Knowing that in our model, the cell migrates by sliding on the surface, the higher $r_{c}$ implies more surface, thus less energetical changes. Finally, as for the rectangular grooves, optimal values of $\lambda^{*}$ and $A^{*}$ exist leading to the best efficiency of the cell. Indeed, for values of $A^{*}$ lower or equal to half the radius of the cell, and $\lambda^{*}$ lower or equal to the radius of the cell, the influence of the surface topography is clearly evident in terms of cell speed and shape. This allows us to draw the main conclusion of our study: surface topography effects are highest for $w^{*} / \lambda^{*}$ around half the size of the cell, and $d^{*} / A^{*}$ around a quarter of the size of the cell.

\section{Conclusion}

In the current study, we proposed a 3D CP model to analyse the cell motility on different surfaces (i.e. flat surface, rectangular parallel and rectangular perpendicular grooves, sinusoidal parallel grooves) in order to quantify the influence of the $\mathrm{CP}$ parameters and the substrate topography on the cell behaviour. The advantage of CP approach is in the ability to model any biological mechanisms of the cell by adding an energy term to the Hamiltonian function of the system. This method makes it possible to isolate specific cell and environment properties, thus it enables individual cell mechanisms analysis. Besides, assuming that the cell moves in accordance to the minimal energy path, CP model is especially suitable for an energy-based analysis. Moreover, we opted for a $3 \mathrm{D}$ environment since we want to study the 3D geometrical aspect of specific roughness on the cell motility.

Our aim was to create a 3D model that enables to quantify the influence of the topography on various cell migration parameters, such as cell speed, contact surface and cell shape. We considered the cell as a homogeneous domain including the cytoplasm (whose elastic behaviour is described by $\lambda_{\text {volume}}$ ) and the membrane (whose elastic behaviour is described by $\lambda_{\text {surface}}$ ). The model accounted for the interactions between the cell and its environment via the two energetic parameters $J_{c s}$ (adhesion energy between the cell and the substrate) and $\mathrm{J}_{\mathrm{cm}}$ (adhesion energy between the cell and the medium). The main outcomes of our study are:

- on random rough surfaces, we have shown that the contact surface between the cell and the substrate increases, leading to a decrease in cell speed;

- the parameter $J_{c s}$ defines the influence of the surface, whether its inhibiting or promoting effect;

- for substrates whose topography is oriented in the direction of migration (i.e. sinusoidal parallel grooves and rectangular parallel grooves), the migration speed was improved. Nonetheless, such an improvement is observed for specific values of the topological parameters of the substrate (i.e. for $d^{*} \mid A^{*}$ and $w^{*} \mid$ $\lambda^{*}$ equal to a quarter and half the cell diameter, respectively). Beyond such values, the cell migration speed starts to decrease;

- comparing the rectangular parallel grooves and the sinusoidal parallel grooves, one may notice that, for equivalent dimensions, the cell migrates more efficiently on the rectangular ones as it has also been experimentally observed;

- for the substrate with rectangular perpendicular grooves, the cell naturally aligns with the groove, and it leads to a drop of the cell speed;

Overall, we have shown that our simplified energetic approach is able to catch the mechanisms behind the cell migration in presence of roughness, and it can predict the response of the cell to 3D micro patterns. Although the interesting and encouraging results, our model presents some limitations that must be addressed. First, at this stage our model does not consider the internal dynamics of the cell which may lead to some incongruities with respect to the experimental data in the literature. Second, the behaviour of the cell does not reproduce the continuous polarisation and depolarisation of its cytoskeleton, which leads to an elongationcontraction movement. From an energetic point of view, this results in the cell storing energy which is later released. Therefore, 
it could be interesting to take into account this phenomenon to observe the influence of the roughness on the evolution of the energy during migration. Finally, we assumed that the adhesion energy of the cell is constant, regardless the roughness. However, the literature has shown that roughness affects the surface energy distribution. As an improvement, the relationship between adhesion energy and roughness should be considered.

\section{CRediT authorship contribution statement}

Thomas Thenard: Methodology, Writing - original draft. Anita Catapano: Writing - review \& editing, Conceptualization, Supervision. Michel Mesnard: Writing - review \& editing. Rachele Allena: Writing - review \& editing.

\section{Declaration of Competing Interest}

The authors declare that they have no known competing financial interests or personal relationships that could have appeared to influence the work reported in this paper.

\section{Acknowledgements}

This work has been funded by RNC Santé of Arts et Métiers, supporting the first author through a PhD scholarship.

\section{Appendix A}

\section{A.1. Values of roughness ratio for each topography}

For each surface defined in Section 2.3, we computed the roughness ratio parameter $r_{c}$, as it is reported in the tables below.

\section{A.2. Determination of the cell position, cell contact surface, and cell speed}

The cell position is defined by the position of its COM. To estimate the migratory path of the cell, we track the position of cell COM each 10 MCS. The speed of the cell is defined as the average speed of the cell on the substrate, calculated as the ratio between the distance crossed by the cell on the substrate and the time

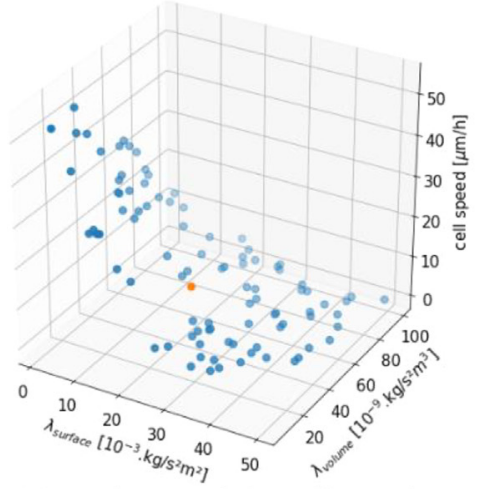

(a) Evolution of the cell speed

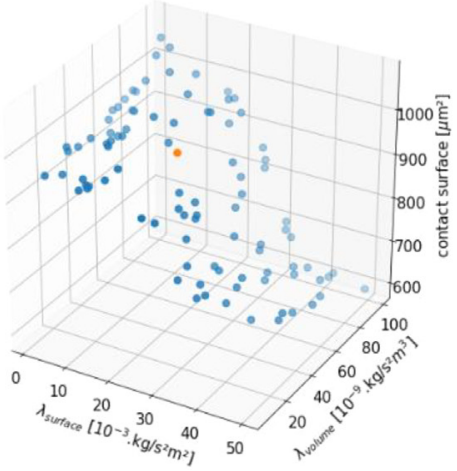

(b) Evolution of the contact surface

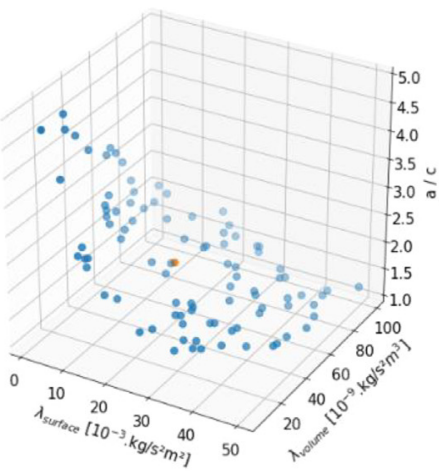

(c) Evolution of the cell elongation

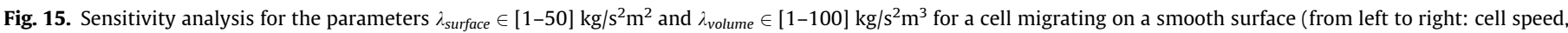

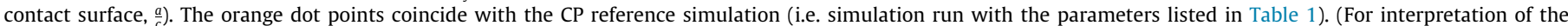
references to colour in this figure legend, the reader is referred to the web version of this article.)

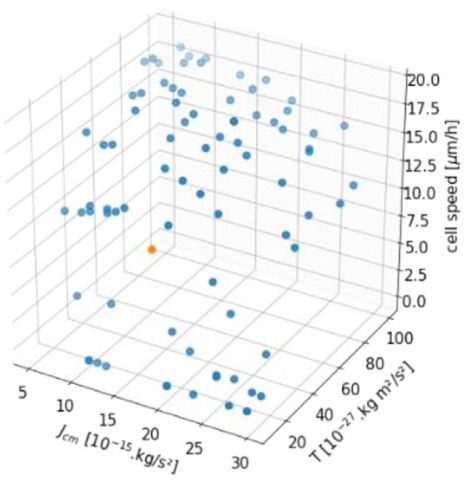

(a) Evolution of the cell speed

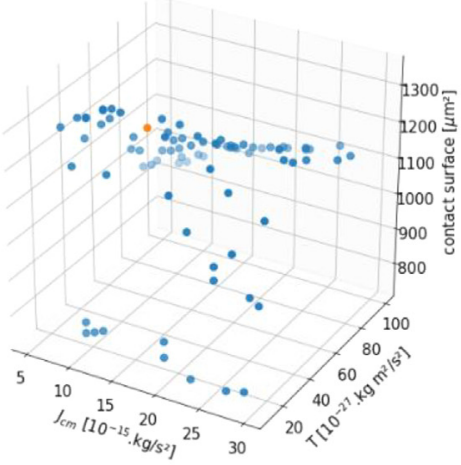

(b) Evolution of the contact surface

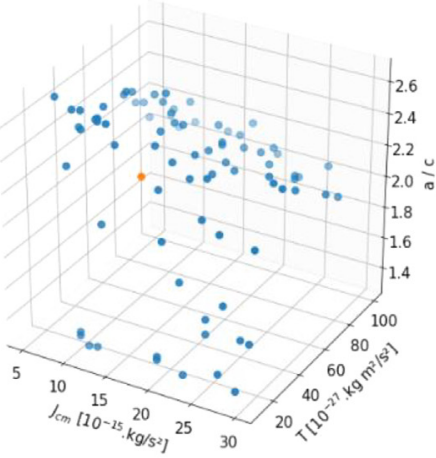

(c) Evolution of the cell elongation

$\left(\frac{a}{c}\right)$

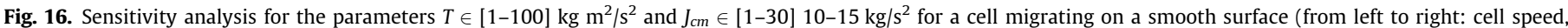

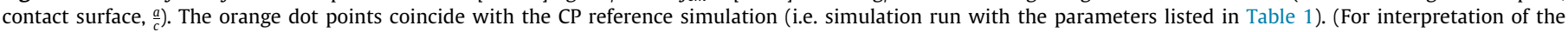
references to colour in this figure legend, the reader is referred to the web version of this article.) 


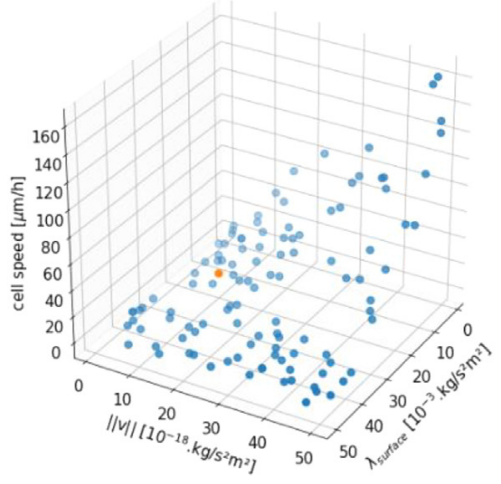

(a) Evolution of the cell speed

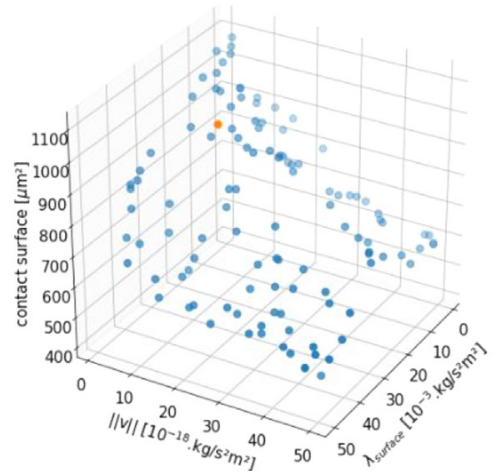

(b) Evolution of the contact surface

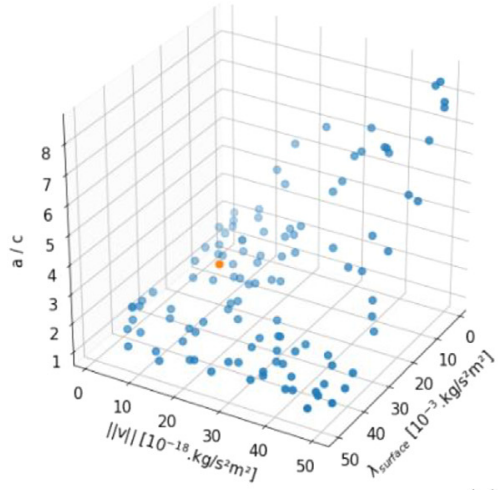

(c) Evolution of the cell elongation $\left(\frac{a}{c}\right)$

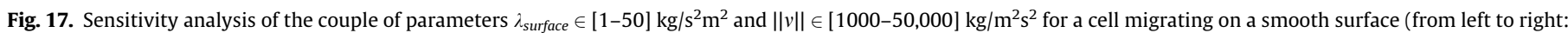

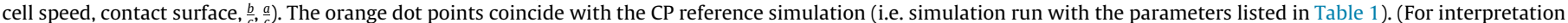
of the references to colour in this figure legend, the reader is referred to the web version of this article.)

required to cross such distance. The model parameters have been calibrated in order to obtain a cell speed of $0.18 \mu \mathrm{m} / \mathrm{s}$ (around $9 \mu \mathrm{m} / \mathrm{h}$ ) (Cheng et al., 2019; Wu et al., 2013), which is in agreement with the experimental data from the literature. Consequently, $1 \mathrm{MCS}$ has been set equal to $10 \mathrm{~s}$. The contact surface of the cell is defined as the number of voxels of the cell neighbouring the substrate. The contact surface is computed every 10 MCS and the average is considered. To analyse the shape of the cell, we assumed that the cell has an ellipsoidal shape. Thus, we measured the 3 main axes a, b, and c (with c the minor axis) of the cell every 10 MCS and we considered the average values for each axis. Then, a parameter was computed: $\frac{a}{c}$ which are used to characterize the cell shape. It has to be noticed that, although a transient phase is observed for each output parameter (i.e. cell speed, contact surface and cell elongation), the duration of such a phase undergoes slight variations intra and inter configurations and it could not be automatically detected. Thus, the output parameters are computed over the time period going from 150 MCS to 8500 MCS.

\section{A.3. Sensitivity analysis}

The influence of the input parameters of the model on the overall behaviour of the cell was determined by performing a sensitivity analysis. Such an analysis has allowed us to set the values of the input parameters to ensure reasonable output parameters (i.e. cell speed, contact surface and cell elongation) according to the literature.

More specifically, the data from the literature show that:

- The contact surface between the cell and a smooth surface is within the $1500 \mu \mathrm{m}^{2}$ (Gallant et al., 2005) - $1740 \mu \mathrm{m}^{2}$ (Lo et al., 2000) range;

- The cell speed on a smooth surface is around $9 \mu \mathrm{m} / \mathrm{h}$;

- The ratio between the cell length and width on a smooth surface goes from 1.5 (Abagnale et al., 2017) to 2.5 (Lee et al., 2016).

The sensitivity analysis was performed for sets of two parameters as follows:

- $\lambda_{\text {surface }}$ and $\lambda_{\text {volume }}$ (Fig. 15)

- the temperature T and the adhesion to the medium $J_{c m}$ (Fig. 16)

- the external potential norm $\|\vec{v}\|$ and $\lambda_{\text {surface }}$ (Fig. 17)

Only one set of parameters at the time was let vary. The values of each set of parameters were randomly chosen for 100 cases. The extremes of the intervals coincide with configurations for which the cell was unable to move on the substrate or the cell moved within the medium rather than on the substrate. We have assessed the sensitivity of the model with respect to these parameters in terms of cell speed, contact surface and cell shape $\left(\frac{a}{c}\right)$.

In Fig. 15 we observe a decrease of the cell speed and of the contact surface with an increase of $\lambda_{\text {surface }}$, regardless of the $\lambda_{\text {volume }}$. As for the shape of the cell, we notice that the cell mostly deforms in the X-Y plane $\left(\frac{a}{c}\right)$ as $\lambda_{\text {surface }}$ increases. According to these outcomes, we set $\lambda_{\text {surface }}=15 \cdot 10^{-3} \mathrm{~kg} / \mathrm{s}^{2} \mathrm{~m}^{2}$ and $\lambda_{\text {surface }}=50.10^{-9} \mathrm{~kg} / \mathrm{s}^{2} \mathrm{~m}^{3}$ (Table 1).

Cell speed and contact surface also decrease as $T$ and $J_{c m}$, increase (Fig. 16). Nonetheless, the contact surface seems to slightly decrease at high value of $T$, due to the high Brownian motion of the cell. In terms of cell shape, the cell remains rather spherical regardless the values of $T$ and $J_{\mathrm{cm}}$. According to these results, we set $J_{c m}=1.10^{-15} \mathrm{~kg} / \mathrm{s}^{2}$ and $T=15.10^{-27} \mathrm{kgm}^{2} / \mathrm{s}^{2}$ (Table 1 ).

In Fig. 17, the higher $\lambda_{\text {surface }}$, the lower the cell speed and the contact surface. Additionally, for high value of $\|v\|$, the cell speed increases up to 10 times the reference value $(10 \mu \mathrm{m} / \mathrm{h})$ and the contact surface significantly decreases, triggering a migration of the cell in the medium. In terms of cell shape, high values of $\|v\|$ provide unnatural elongations of the cell (over 10 times the width). According to these outcomes, we set $\|v\|=10.10^{-18} \mathrm{~kg} / \mathrm{s}^{2} \mathrm{~m}^{3}$ and $\lambda_{\text {surface }}=15 \cdot 10^{-3} \mathrm{~kg} / \mathrm{s}^{2} \mathrm{~m}^{2}$ (Table 1 ).

\section{References}

Gaviria, L., Salcido, J.P., Guda, T., Ong, J.L., 2014. Current trends in dental implants. J Korean Assoc. Oral Maxillofac. Surg. 40 (2), 50-60. https://doi.org/10.5125/ jkaoms.2014.40.2.50.

Albrektsson, T., Brånemark, P.I., Eriksson, A., Lindström, J., 1978. The preformed autologous bone graft. An experimental study in the rabbit. Scand J. Plast. Reconstr. Surg. 12 (3), 215-223.

Albrektsson, T., Brånemark, P.I., Hansson, H.A., Lindström, J., 1981. Osseointegrated titanium implants. Requirements for ensuring a long-lasting, direct bone-toimplant anchorage in man. Acta Orthop. Scand 52 (2), 155-170.

Liddell, R., Ajami, E., Davies, J.E., 2017. Tau $(\tau)$ : A new parameter to assess the

osseointegration potential of an implant surface. Int. J. Oral Maxillofac. Implants 32 (1), 102-112. https://doi.org/10.11607/jomi.4746.

Wennerberg, A., Albrektsson, T., et al., 2009. Effects of titanium surface topography on bone integration: A systematic review. Clin. Oral Implants Res., 20(4), 172-

184. doi: 10.1111/j.1600-0501.2009.01775.x. 
Huang, H.-H., Ho, C.-T., Lee, T.-H., Lee, T.-L., Liao, K.-K., Chen, F.-L., et al., 2004. Effect of surface roughness of ground titanium on initial cell adhesion. Biomol. Eng., 21(3), 93-97. doi: 10.1016/j.bioeng.2004.05.001.

Anselme, K., et al., 2000. Qualitative and quantitative study of human osteoblast adhesion on materials with various surface roughnesses. J. Biomed. Mater. Res., 49(2), 155-166. doi: 10.1002/(SICI)1097-4636(200002)49:2<155::AIDJBM2>3.0.CO;2-J.

Anselme, K., Bigerelle,M., et al., 2014. On the relation between surface roughness of metallic substrates and adhesion of human primary bone cells. Scanning, 36(1), 11-20. doi: $10.1002 /$ sca.21067.

Andrukhov, O. et al., 2016. Proliferation, behavior, and differentiation of osteoblasts on surfaces of different microroughness. Dent. Mater. 32 (11), 1374-1384. https://doi.org/10.1016/j.dental.2016.08.217.

Wu, C., Chen, M., Zheng, T., Yang, X., 2015. Effect of surface roughness on the initial response of MC3T3-E1 cells cultured on polished titanium alloy. Biomed. Mater.

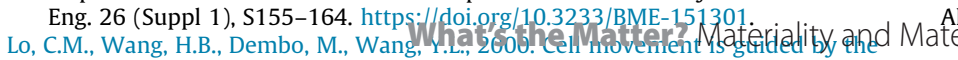
rigidity of the substrate. Biophys. J. 79 (1), 144-152.

Chang, C.-H., Lee, H.-H., Lee, C.-H., 2017. Substrate properties modulate cell membrane roughness by way of actin filaments. Sci. Rep. 7 (1), 9068. https:// doi.org/10.1038/s41598-017-09618-y.

Discher, D. E., Janmey, P., Wang, Y.-L., et al., 2005. Tissue cells feel and respond to the stiffness of their substrate. Science, 310(5751), 1139-1143. doi: 10.1126/science.1116995.

Raab, M., Swift, J., Dingal, P. C. D. P., Shah, P., Shin, J.-W., Discher, D. E., et al., 2012. Crawling from soft to stiff matrix polarizes the cytoskeleton and phosphoregulates myosin-II heavy chain. J. Cell Biol., 199(4), 669-683. doi: $10.1083 /$ jcb.201205056.

Novaes, A.B., de Souza, S.L.S., de Barros, R.R.M., Pereira, K.K.Y., Iezzi, G., Piattelli, A., 2010. Influence of implant surfaces on osseointegration. Braz. Dent. J. 21 (6), 471-481.

Lamers, E. et al., 2010. The influence of nanoscale topographical cues on initial osteoblast morphology and migration. Eur. Cell Mater. 20, 329-343.

Kaiser,J.-P., Reinmann, A., Bruinink, A., et al., 2006. The effect of topographic characteristics on cell migration velocity. Biomaterials, 27(30), 5230-5241. doi: 10.1016/j.biomaterials.2006.06.002.

Gallant, N. D., Michael, K. E., García, A. J., et al., 2005. Cell adhesion strengthening: Contributions of adhesive area, integrin binding, and focal adhesion assembly. Mol. Biol. Cell., 16(9), 4329-4340. doi: 10.1091/mbc.E05-02-0170.

Ponsonnet, L., et al., 2003. Relationship between surface properties (roughness, wettability) of titanium and titanium alloys and cell behaviour. Mater. Sci. Eng. C, 23(4), 551-5603. doi: 10.1016/S0928-4931(03)00033-X.

Kim, M.-C., Neal, D. M., Kamm, R. D., Asada, H. H., et al., 2013. Dynamic modeling of cell migration and spreading behaviors on fibronectin coated planar substrates and micropatterned geometries. PLOS Comput. Biol., 9(2), e1002926. doi: 10.1371/journal.pcbi.1002926.

Albert, P. J., Schwarz, U. S., et al., 2014. Dynamics of cell shape and forces on micropatterned substrates predicted by a Cellular Potts model. Biophys. J., 106 (11), 2340-2352. doi: 10.1016/j.bpj.2014.04.036

Graner, F., Glazier, J. A., et al., 1992. Simulation of biological cell sorting using a twodimensional extended Potts model. Phys. Rev. Lett., 69(13), 2013-2016. doi: 10.1103/PhysRevLett.69.2013.

Swat, M.H., Thomas, G.L., Belmonte, J.M., Shirinifard, A., Hmeljak, D., Glazier, J.A., 2012. Multi-scale modeling of tissues using Compucell 3D. Methods Cell. Biol. 110, 325-366. https://doi.org/10.1016/B978-0-12-388403-9.00013-8.

Scianna, M., Preziosi, L., Wolf, K., 2013. A Cellular Potts model simulating cell migration on and in matrix environments. Math. Biosci. Eng. 10 (1), 235-261.
Chong, B., Gong, Z., Lin, Y., et al., 2016. Modeling the adhesive contact between cells and a wavy extracellular matrix mediated by receptor-ligand interactions. J. Appl. Mech., 84(1), 011010-011010 7. doi: 10.1115/1.4034931.

Decuzzi, P., Ferrari, M., et al. 2010. Modulating cellular adhesion through nanotopography. Biomaterials, 31(1), 173-179. doi: 10.1016/j. biomaterials.2009.09.018.

Metropolis, N., Rosenbluth, A.W., Rosenbluth, M.N., Teller, A.H., Teller, E., 1953. Equation of state calculations by fast computing machines. J. Chem. Phys. 21 (6), 1087-1092. https://doi.org/10.1063/1.1699114.

Deshpande, S. M., Subba Raju, P., et al., 1988. Monte carlo simulation for molecular gas dynamics. Sadhana, 2(1), 105-123. doi: 10.1007/BF02745661.

Ilina, O., Bakker, G.-J., Vasaturo, A., Hofmann, R. M., Friedl, P., et al., 2011. Twophoton laser-generated microtracks in 3D collagen lattices: principles of MMPdependent and -independent collective cancer cell invasion. Phys. Biol., 8(1), 015010. doi: 10.1088/1478-3975/8/1/015010.

Allena, R., Scianna, M., Preziosi, L., et al., 2016. A Cellular Potts model of single cell

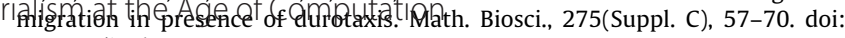
10.1016/j.mbs.2016.02.011.

Rosales-Leal, J.I. et al., 2010. Effect of roughness, wettability and morphology of engineered titanium surfaces on osteoblast-like cell adhesion. Colloids Surf A Physicochem. Eng. Asp. 365 (1), 222-229. https://doi.org/10.1016/ j.colsurfa.2009.12.017.

Han, J., Menon, N. V., Kang, Y., Tee, S.-Y., et al., 2015. An in vitro study on the collective tumor cell migration on nanoroughened poly(dimethylsiloxane) surfaces. J. Mater. Chem. B, 3(8), 1565-1572. doi: 10.1039/C4TB01783H.

Ranella, A. Barberoglou, M., Bakogianni, S., Fotakis, C., Stratakis, E., et al., 2010 Tuning cell adhesion by controlling the roughness and wettability of 3D micro/nano silicon structures. Acta Biomater., 6(7), 2711-2720. doi: 10.1016/j. actbio.2010.01.016.

Dalton, B.A. et al., 2001. Modulation of epithelial tissue and cell migration by microgrooves. J. Biomed. Mater. Res. 56 (2), 195-207. https://doi.org/10.1002/ 1097-4636(200108)56:2<195::AID-JBM1084>3.0.CO;2-7.

Uttayarat, P., Chen, M., Li, M., Allen, F. D., Composto, R. J., Lelkes, P. I., et al, 2008 Microtopography and flow modulate the direction of endothelial cell migration. Am. J. Physiol. Heart Circ. Physiol., 294(2), H1027-1035. doi: 10.1152/ ajpheart.00816.2007.

Cheng, D., Jayne, R. K., Tamborini, A., Eyckmans, J., White, A. E., Chen, C. S., et al., 2019. Studies of 3D directed cell migration enabled by direct laser writing of curved wave topography. Biofabrication, 11(2), 021001. doi: 10.1088/17585090/ab047f.

Hu, J., Hardy, C., Chen, C.-M., Yang, S., Voloshin, A.S., Liu, Y., . Enhanced cell adhesion and alignment on micro-wavy patterned surfaces. PLOS ONE 9, (8). https://doi. org/10.1371/journal.pone.0104502 e104502.

Andersson, A.-S., Olsson, P., Lidberg, U., Sutherland, D., août 2003,. The effects of continuous and discontinuous groove edges on cell shape and alignment. Exp. Cell Res. 288 (1), 177-188. https://doi.org/10.1016/S0014-4827(03)00159-9.

Wu, T.-H., Li, C.-H., Tang, M.-J., Liang, J.-I., Chen, C.-H., Yeh, M.-L., et al., 2013. Migration speed and directionality switch of normal epithelial cells after TGF$\beta 1$-induced EMT (tEMT) on micro-structured polydimethylsiloxane (PDMS) substrates with variations in stiffness and topographic patterning. Cell Commun. Adhes., 20(5), 115-126. doi: 10.3109/15419061.2013.833194.

Abagnale, G. et al., 2017. Surface topography guides morphology and spatial patterning of induced pluripotent stem cell colonies. Stem Cell Rep. 9 (2), 654666. https://doi.org/10.1016/j.stemcr.2017.06.016.

Lee, K., et al., 2016. Contribution of actin filaments and microtubules to cell elongation and alignment depends on the grating depth of microgratings. J. Nanobiotechnol., 14(1), 35. doi: 10.1186/s12951-016-0187-8. 